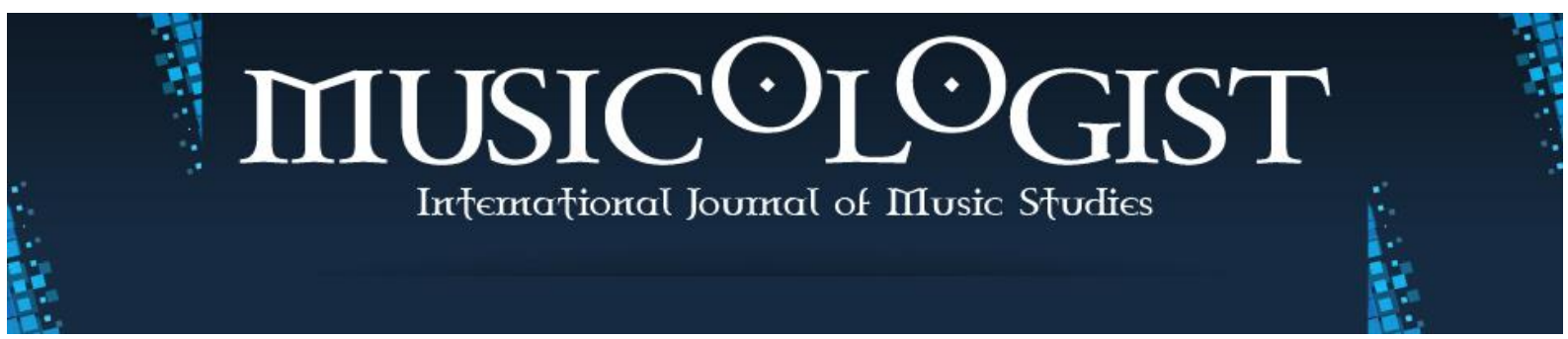

Trabzon University State Conservatory @

Volume 4 Issue 2 December 2020

Research Article

Musicologist 2020. 4 (2): 138-167

DOI: $10.33906 /$ musicologist.782094

FRANK SCHERBAUM

Universität Potsdam, Germany

fs@geo.uni-potsdam.de

orcid.org/0000-0002-5050-7331

NANA MZHAVANADZE

Universität Potsdam, Germany

mzhavanadze@uni-potsdam.de

orcid.org/0000-0001-5726-1656

\title{
Svan Funeral Dirges (Zär): Musical Acoustical Analysis of a New Collection of Field Recordings
}

\begin{abstract}
This paper is a companion paper to Mzhavanadze \& Scherbaum (2020). Jointly, the two papers describe the results of an interdisciplinary study of three-voiced Svan funeral dirges, known as zär in Svan and zari in Georgian. In the present paper, to which we refer as paper 1 , we analyze the musical acoustical properties of a new set of field recordings collected during an ethnomusicological field expedition to Georgia in 2016. The aim of the study is to investigate the tonal organization of eleven different performances of six different variants of zär, performed by singers from different villages. For some of the performances, we observe a strong gradual pitch rise of up to 100 cents per minute. The intra-variant differences in the performances of different groups of singers were observed to be remarkably different, including the use of significantly different harmonic tuning systems. In contrast, two subsequent performances of the Mest'ia variant of zär by a group of singers recorded in Zargāsh were essentially identical. This demonstrates the widespread absence of improvisational elements in these two performances. One of the most interesting results of our analysis is the observation that the musical structure of $z a ̈ r$, expressed, for example, in its ambitus, the complexity of its melodic progression, and its harmonic chord inventory, change systematically along the course of the Enguri valley.
\end{abstract}

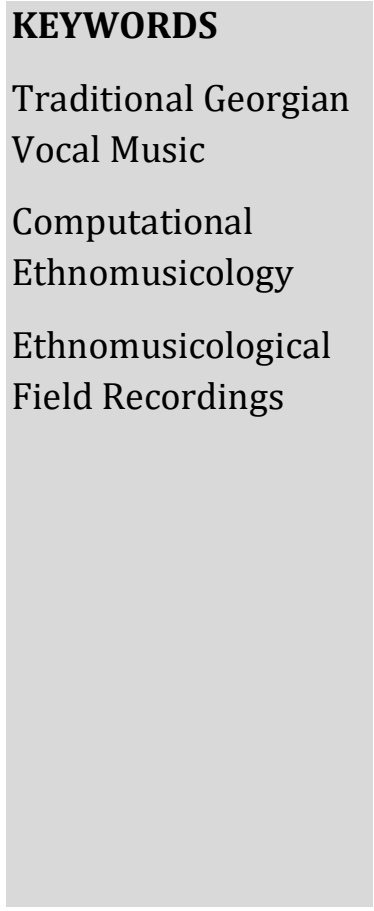




\section{Preface}

The two companion papers in this issue describe the results of a study of Svan funeral dirges (zär), in which we combine a computational/acoustical and a classical (ethno)musicological perspective. This study has been a very challenging, but incredibly enriching experience, which took both of us out of our professional comfort zones in the sciences and humanities. It also made us realize how many more aspects should have been incorporated in our study. Due to the limited size of the individual articles, here we can only provide very superficial references to anthropological, historical, and linguistic sources, although we consider them indispensable for the overall understanding of the phenomenon of zär. The purpose of this preface is to partially make up for this deficiency by providing a short literature review and a brief discussion of the zär-related discourses taking place in these fields ${ }^{1}$.

It is also worth mentioning that there have been other considerable efforts in the past to record Svan vocal music, first with phonographs, and later with tape recorders. Unfortunately, many recordings of Svan songs from the early days of the last century have not survived the time. The few audio files obtained are mostly of a very poor quality. On the other hand, the Tbilisi Conservatory has also carried out recordings since the 1950s. Unfortunately, many of these recordings (mainly field recordings from 1980-1990s) were lost during the renovation work at the conservatoire in the late 90 s. A small number of more recent audio recordings were made by the ethnomusicologists Erkvanidze and Matiashvili in 2004 (recordings of approximately 25 songs in Lower Svaneti), and between 2007 and 2010 by the State Center of Folklore, both in Lower- and Upper Svaneti, partly with several microphones and in a mobile recording studio. In addition, within the crowd-funded Svan Recording Project performed by American singer Carl Linich in 2010 with members of the Riho Ensemble in Lenjār, 32 songs were supposedly recorded. However, it is unclear whether this project was successfully completed.

All the above-mentioned initiatives have in common that the recordings were purely acoustic. Even with recordings with separate microphones (as in some of the more recent projects), the separability of the individual voices is very limited. In the context of our

\footnotetext{
${ }^{1}$ All the historical, ethnographical, anthropological and cultural-sociological material on the dirge, which we have collected in combination with the generation of the meta-data of the field work of 2016, is publicly accessible through the Lazar archive (https://lazardb.gbv.de).
} 
own work on the generation and propagation of body-vibration during singing (Scherbaum et al., 2015), we have tested the acoustic separability of individual voices with directional microphones under studio conditions and found that this is lost very quickly even under idealized conditions when singers sing with differing intensity (which they definitely do in Svaneti). In conclusion, to our knowledge the acquired research corpus is currently the only one of suitable size and quality for the application of modern computational/acoustical analysis.

\section{Zär as ritualized dirge}

Ritualized mourning2 in its wide variety of manifestations (solo, choral, etc.) is a universal phenomenon attested all over the world, which can be heard at culturally and geographically distinct areas on earth. Examples of it include: fuatanga in the Tikopia island (Love \& Kaeppler, 2017: 853-855; Firth \& McLean, 2006), dawawa in Central America (Graham, 1984), iavsema in Mordovia, Russia (Jordania, 2006: 663), and Albanian vajtim (Kondi, 2012). In Svaneti (as well as in other parts of Georgia), in addition to the local equivalents of the funeral forms listed above, there is a musically organized funeral hymn, aka $z a ̈ r^{3}$, the equivalent of which does not seem to be found anywhere else. To be more precise, on the one hand, the Svan funeral reveals a responsorial form of keening by both men and women (Azikuri, 2002), whose performance is based on human emotion and completely improvised, and on the other hand, it includes group male chanting, which is a well-organized and coordinated musical practice without a verbal text, composed with peripheral vocabulary (Tsuladze, 1971; Bolle Zemp, 1997).

\footnotetext{
2 To avoid confusion with using the controversial terms such as: keening, lamenting, wailing, crying, etc. applied to describe ritualized mourning soundscape, in the article we will employ the keening for all types of mourning sound manifestations based on improvisational expression of sorrow over loss (solo, responsorial, etc.) and dirge (or chant) for organized polyphonic phenomena such as zär. This will put a clear line between two distinctive and radically different ritual mourning styles sharing the same functional locus.

${ }^{3}$ To ensure that the transcription of Svan texts (including proper names) is close to the original and reflects the phonetic peculiarities of Svan language, we have combined two transcription systems: for consonants - romanization of Georgian via using Latin script (national system, 2002; https://en.wikipedia.org/wiki/Romanization_of_Georgian); for vowels and some Svan-specific consonants - $\quad$ TITUS http://titus.fkidg1.uni-frankfurt.de/didact/caucasus/kaukvok.htm\#SvanUBal and http://titus.uni-frankfurt.de/didact/caucasus/kartlaut.htm
} 


\section{Origin and purpose of zär}

The references to the origins of the context and performance form of $z \ddot{r} r$ in Svaneti are not clear or consistent. Today it is strictly labeled as a mourning ceremonial dirge, however, earlier accounts regarding its function and role in mourning ritual, as well as its verbal content, vary. According to some, it is a kind of funerary "travelling "song" (Paliashvili, 1909; Phillips-Wolley, 1883: 95, 96), while some early authors, portraying funeral ceremonies, including the last procession to the cemetery, never mention zär, but describe lamentation of women and men instead (including group wailing) (Goltsev, 1933: 92,93; Dadwani, 1973: 12-14). Some authors claim zär to have been performed at the funeral of only the happy deceased (Akhobadze, 1957: 21; Phillips-Willey, 1883: 95, $96)^{4}$. Today, however, it is sung at any funeral.

Besides, some earlier references claim that zär was sung with text (Paliashvili, 1909), which served as a farewell "speech" about the deceased's deeds and personality. However, as of today, considering the musical peculiarities of zär, conventional verbal text seems impossible to fit in. ${ }^{5}$

The original purpose of $z a ̈ r$, which, according to some Georgian scholars (Arakishvili, 1950: 21; Mzhavanadze, 2018), has ancient roots, remains vague ${ }^{6}$. The etymology of the name zär is also obscure, and since it is common for the mourning ritual repertoire in other parts (zari in Georgian7, azar in Abkhazian ${ }^{8}$ ), a complex comparative study is needed to reveal how they are related. The musical language of this three-voice chant also

\footnotetext{
${ }^{4}$ It is believed that some very old deceased was "happy" meaning that his entire family survived his death and thus he never suffered the loss of younger family members. Today the same function (of chanting for a "happy" deceased) is only attributed to another hymn-type "song" $k$ 'viria.

${ }^{5}$ Judging by the observation of the current state and status of this multifaceted and sophisticated phenomenon, we can say that zär is not an emotion-driven spontaneous mourning behavior such as the planctus and seems to be more like the discourse which is a framed, rationalized, and stylized expression of grief or a "lyrical resolution of suffering" (Lloyd, 1980:407). The emotional outreach and impact of zär is controversial and if for some it sounds like a festive hymn (Paliashvili, 1909), for others its musical content can be extremely mourning and/or full of mystics and, therefore, people avoid "singing" it at any other time but funeral. During the field work in 2016, our informants refused to do zär inside one's house and we had to go away from the village and find a deserted place to record them.

6 The word zär does not seem to have the mourning connotation until the 17-18th century which complicates the matter even more.

${ }^{7}$ In Rach'a, apart from zari, another form of lament is zruni, which is a lament with a text telling about the deceased. The song draws a special interest because it is sung in only two Upper Rach'an villages: Ghebi and Glola which historically were inhabited by Svans.

${ }^{8}$ Accounts on azar are not consistent. More about this issue see at https://lazardb.gbv.de/search
} 
raises an interest about its relationship to other hymn-type Svan repertoire, which shares some verbal and musicological characteristics.

Within the scope of the theories of origin of Georgian polyphony by the example of Svan repertoire (including zär) some authors propose the three-part forms originating from one voice and gradually framed by a parallel fifth (Aslanishvili, 1954: 37, 85, 97). On the contrary, Gogotishvili (1994) introduces the theory of the third voice arising later to fill the space within the fifth interval.

In contrast to the theory of ancient origins of Svan sacred repertoire (including zär), Gabisonia (2012) suggests the Svan hymn-type songs to be paganized (simplified) versions of Georgian church music, which he assumes to have been sung during a liturgy in Svaneti in the middle ages. He claims that due to historical hardships, the liturgical practices gradually stopped in Svaneti but people kept the chants in memory trying to employ them in non-liturgical sacred ceremonies. He furthermore assumes that during this long process only bits of words would survive in the form of vowels and syllables. These would be coupled with fragments of the music which represents a kind of compilation of the phrases which are difficult to perceive as accomplished musical image(s). The author sees compositional similarities between zär and church chants (e.g. "melodic continuum" held with one syllable) as one of the arguments for this connection (ibid) ${ }^{9}$.

Bolle Zemp was the first to investigate musical structure of zär in relation with the 'text' (Bolle Zemp, 1997; 2001). She was also the first to apply quantitative methods to the analysis of zär in order to improve the interpretation of "non-semantic" text and explain some musical peculiarities of zär. Her interdisciplinary approach involves the attempt to understand the ethnographical context of the chant and the investigation of its linguistic and musicological aspects. Employing the tools accessible at that time, she processed the chant through sonographic images and analyzed the musical content of the verbal 'text', explored all the possible references of the utterances employed in $z \ddot{a} r$, and visualized the

\footnotetext{
${ }^{9}$ Although Z. Paliashvili also considers that the hymn was simply deformed over times and that the preserved syllables are remnants of text which had been forgotten, he does not make a notice of church music here (Paliashvili, 1909). Note that A. Dirr's (1914) article on Svan music is a condensed version of Paliashvili's collection of Georgian (including Svan) songs published in 1909. Therefore, the review of the songs as well as the notated transcriptions belong to Z. Paliashvili (ibid).
} 
results in the form of sonograms. Based on the results of her multi methodological analysis, Bolle Zemp suggests a strong correlation between words and music. She hypothesizes that the verbal text takes a leading role in shaping the musical structure of $z \ddot{a r}$. She assigns semantic importance to the core utterance woi, arguing that as an utterance of mourning connotation, it lies at the root of several vocal formulas of the chant. In her view, 'singers' emphasize human emotions such as pain, dignity, etc. by modification of the sound characteristics of spoken language, e.g. by formation of vowels and consonants in different ways, by manipulation of the interjections, and by stylization of expressions of the spoken language through certain vocal process (valorization, descending glissandi, nasalization). In her view, the structure of the movement of voices, the duration of a sound, the sequence of concomitants, and the interrelationship of consonant and dissonance chords is greatly conditioned by the 'text', which coordinates the musical process (Bolle Zemp, 1997; 2001).

In prior work Mzhavanadze (2018) investigated the ethnological context of zär, and explored etymological, linguistic, and musicological aspects via manual analysis of both archive recordings, as well as the variants documented together with F. Scherbaum during fieldwork in Svaneti in 2016 (Scherbaum \& Mzhavanadze, 2018). This included a comparative review of some musicological characteristics of the chant as well. She discussed and developed a wide spectrum of hypotheses related to the issue of origins of $z a ̈ r$, the "asemantic" texts, etymology, polyphonic form, etc. She also challenged mainstream theories of stadial development of Georgian polyphony (Mzhavanadze, 2018: 175-233). Some of the hypotheses have been tested, and some discussions have been reinforced and revisited in the present paper as well.

While concentrating mainly on the problem of the origins of zär, some authors investigate semantic and functional aspects of the chant (Kalandadze-Makharadze, 2005) to prove its ancient roots, others make the same assumption based mainly on the arguments related to its musical syntaxes, such as: a narrow span of voice movements, utterancebased musical phrases, syllable and vowel based, "non-semantic text", combination of simple two- and three-part harmonic segments, step-wise movement of voices, sharp alteration of mode or neutral mode, the sacred context and poly-functionality (cult of the dead) (Arakishvili, 1950: 9; Aslanishvili, 1954: 87; Rosebashvili, 1982: 45-48). 


\section{The field expedition of 2016}

During the summer of 2016, we performed a two-month ethnomusicological field expedition to Upper Svaneti and Svan eco-villages. On this occasion, we collected a new research corpus of traditional Georgian songs, prayers, and lamentations, consisting of audio material of more than one hundred songs, including more than one thousand audio tracks recorded with different types of sensors (headset and larynx microphones attached to the singers' bodies, a stereo microphone in front of the whole ensemble, and a directional microphone on the video camera), video recordings, as well as written transcripts of the extensive interviews with the performers. (Scherbaum \& Mzhavanadze, 2018; Scherbaum et al., 2018; Scherbaum et al., 2019). A particular gem in this corpus is the set of recordings of three-voiced male funeral songs, known as zär in Svan and zari in Georgian, part of which were recorded in their natural context at funerals. Although every Svan village used to have its own variant of zär, as we were told by local informants (e. g. by Murad Pirtskhelān in Lakhushd), it is assumed today that only 11 different variants have survived. The collection which was obtained during the 2016 field campaign, and which is the focus of the present paper, consists of 11 recordings of 6 different variants of $z \ddot{a} r$. It therefore represents more than half of the zär repertoire believed to still exist. This makes it not only a unique dataset for ethnomusicological research, but also an important cultural document of Svan funeral rites. 


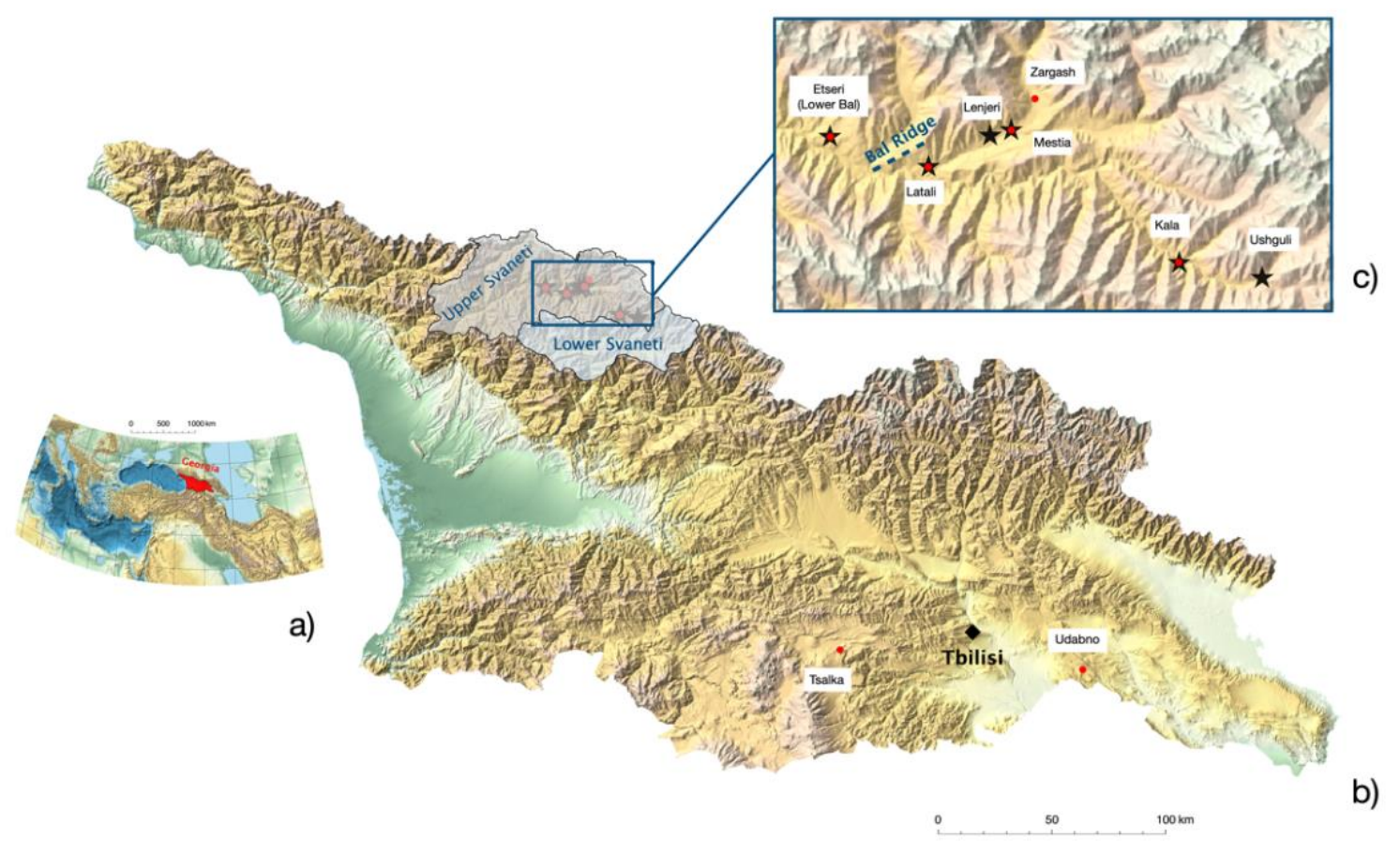

Figure 1. Geographical situation. a) The location of Georgia in its regional context. b) Study area and recordings sites (marked by red solid circles) of the field expedition of 2016. c) Locations of recording sites (red solid circles) and locations of origin of zär (black stars) within Upper Svaneti. The Bal ridge (altitude-wise) divides the Lower Bal and Upper Bal regions of Upper Svaneti.

The recording locations and the locations of origin of the different zär variants are shown in Figure 1 by red solid circles and black stars, respectively. Apart from the Upper Svaneti area, the field work also covered the eco-migrant Svan communities of Didgori, Tsalka, and Udabno, outside Svaneti, near Georgia's capital, Tbilisi (Figure 1). These recordings may become especially precious because the villages are populated by eco-migrant Svans who immigrated from different communities of Upper Svaneti a few decades ago. The analysis of these performances, we believe, might help to retrieve information about the changes (if any) in the repertoire (including zär) and their 'lives' after they have 'dislocated' from their homes to a new geographical and partially social context.

All the recordings of the 2016 field expedition have been made publicly available and can be accessed either through the open access long-term archive at the University of Jena, which also hosts the field report (which also contains all the ethnographic information about the music performers), the videos of the performances, and all other meta data (https://lazardb.gbv.de/search; see Scherbaum et al., 2018 for details), or through the research repository at the University of Erlangen of the GVM project 

see Figure 2) .

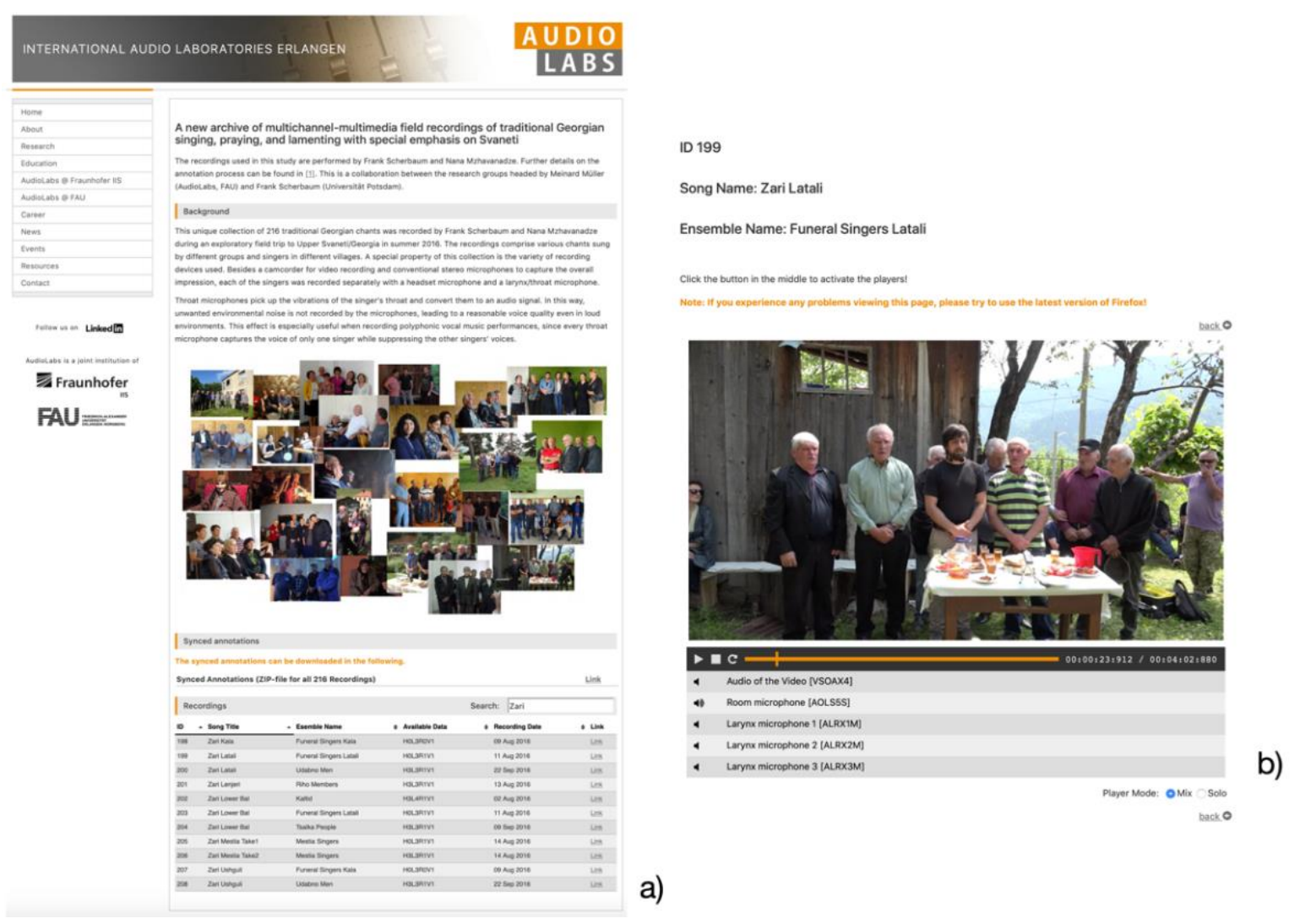

Figure 2. Web interface of the research repository hosted at the University of Erlangen which allows access to the new corpus of zär recordings (audio-, video-, and larynx microphones) ${ }^{10}$. a) top level menu showing the meta data of all zär recordings in the repository. b) For an individual selected performance, shown here for the Lat'li zär (GVM-ID 199), one can playback individual tracks or combinations thereof together with the video of the performance.

The technical quality of the data is good to excellent. All recordings were done as multimedia recordings, in which a high-resolution $(4 \mathrm{~K})$ video stream is combined with a stream of 3-channel headset microphone recordings (one for each voice group), a stream of 3-channel larynx microphone recordings (one for each voice group as well), and a conventional stereo recording. The systematic use of larynx microphones, which to our knowledge has never been done before in ethnomusicological field expeditions, was motivated by the results of a pilot study in Upper Svaneti in 2015, which showed that larynx microphones allow the undistorted documentation of the contribution of each singer while all of them are singing together in their natural context (Scherbaum et al.,

\footnotetext{
${ }^{10}$ Access information can be obtained from the first author (fs@geo.uni-potsdam.de).
} 
2015). In addition, larynx microphone recordings were also shown to contain essential information in relation to a singer's voice regarding pitch, intonation, timbre, and voice intensity, which allows the application of computer-based methods to document and analyze vocal music of the oral tradition in new ways, e. g. to apply computerized pitch analysis techniques to determine the fundamental frequency (F0) trajectories and their microtonal structure, to study the tuning systems used by the singers, as well as possible interactions between singers (Scherbaum et al., 2015; Scherbaum, 2016).

\section{Tonal organization}

In this section, we will discuss the tonal organization derived from the acoustic analysis of the 11 zär recordings from the 2016 field expedition. ${ }^{11}$ In this context, we try to derive a quantitative representation of what happens melodically and harmonically during the performance of a zär in such a way, that it does not require a transcription into a Western notation system. Rather, we consider the tuning system used by the individual singers as part of the characteristics to be determined in the course of our analyses. This was greatly facilitated by the fact that during this field expedition (in addition to headset, and stereomicrophones) larynx microphones were used systematically (Scherbaum et al., 2018; 2019). Since larynx microphone recordings of individual singers are practically unaffected by the voices of co-singers (Scherbaum, 2016), computer-aided determination of the fundamental frequencies (F0) of individual voices can be achieved with algorithms for monophonic signals, for which a number of stable algorithms exist. In this study we use the TONY software by Mauch et al. (2015). In addition to the analysis of the fundamental frequency trajectories of the signals (also referred to as pitch trajectories or pitch tracks ${ }^{12}$ with the PYIN algorithm, this program also performs an algorithmic determination of the sung notes. Furthermore, it allows subsequent interactive editing of the note objects as well as the input of the song lyrics. The results of these processing steps are illustrated in Figure 3 for the three voices of the Ushgul zär, performed during a funeral in K'āl on August 9, 2016. The corresponding audio and video tracks can be found on the Erlangen research repository under GVM-ID 207.

\footnotetext{
${ }^{11} \mathrm{~A}$ discussion of the tonal organization of traditional Georgian music as a general topic is outside the scope of the present paper. A review of the related discourse can be found in Scherbaum et al. (2020).

${ }^{12}$ For simplification, we use the term pitch, which is a psychoacoustic quantity and cannot be measured directly, interchangeably with fundamental frequency F0, which can be determined from audio signals using so-called pitch tracking algorithms (e.g. Mauch et al., 2015).
} 


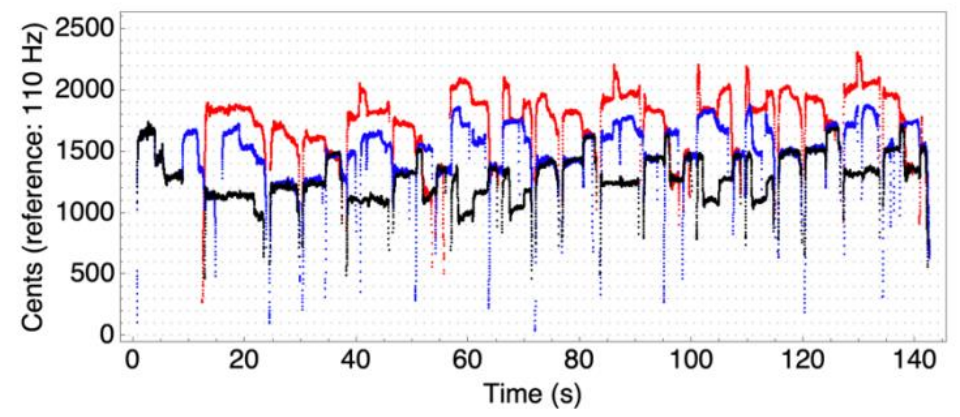

a)

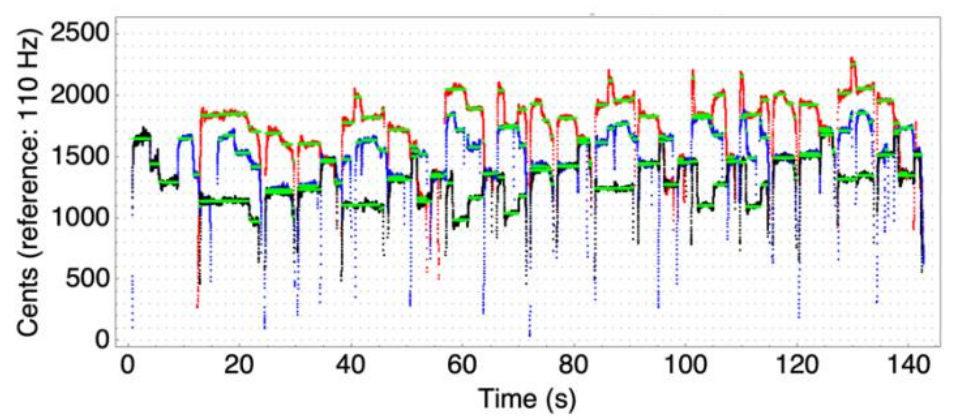

b)

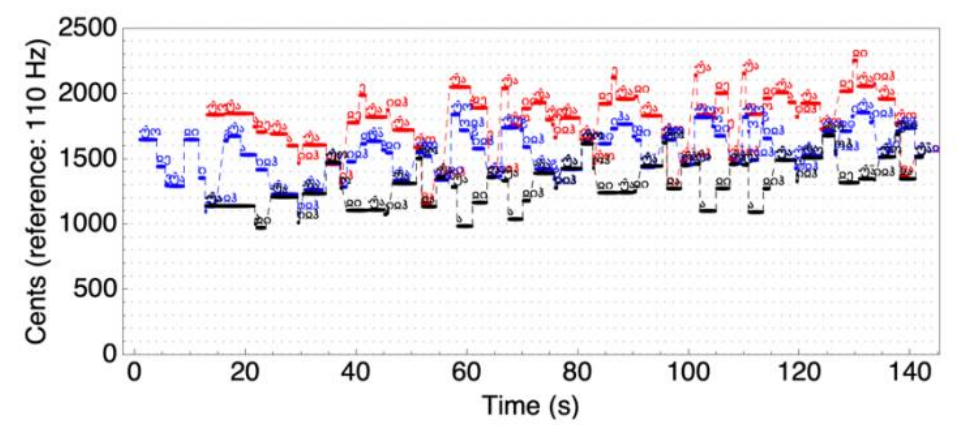

c)

Figure 3. a) F0 trajectories (pitch tracks) for the three voices of the Ushgul zär (GVM-ID 207), performed during a funeral in K'āl on August 9, 2016. b) pitch trajectories superimposed by the corresponding note pitches (green horizontal lines). c) note trajectories with added lyrics. All F0 values are given in cents with respect to a reference frequency of $110 \mathrm{~Hz}$.

Figure 3 a) shows the raw F0 trajectories, Figure $3 b$ ) the superposition of the raw F0 trajectories with the corresponding note objects (green horizontal lines), and Figure 3c) the note trajectories with the inserted lyrics. The red, blue, and black lines in Figure 3 correspond either to the F0-trajectories (in Figure 3a and b) or to the note trajectories (in Figure 3c) of the top, middle, and bass voice, respectively. We convert all the estimated F0-values (given in Hertz) into cents by using

Fcents (f) := $1200 \cdot \log 2$. (f/ fref).

The use of the cents scale in ethnomusicology goes back in time as far as to the last decades of the $19^{\text {th }}$ century (Ellis, 1885). Fcents is actually an interval measure, which measures the distance (in cents) between frequency f (in $\mathrm{Hz}$ ) and a reference frequency 
fref (in Hz). In the following, we define fref $=110 \mathrm{~Hz}$, which corresponds to a frequency of two octaves below the concert pitch of $440 \mathrm{~Hz}$. Through the transformation into the cents domain, one accounts for the logarithmic nature of pitch perception ${ }^{13}$.

Several properties are easily noticeable in Figure 3. First, it can be seen that the zär starts with a monophonic part which lasts for roughly 10 seconds. It is followed by the threevoiced part, which lasts for more than 2 minutes, and during which the individual voices are mostly clearly separated vertically, except for the times when all three voices meet at the same pitch. There are no signs of voice crossing. Hence, in terms of the chord progression characteristics, the function of the individual singers (bass, middle, top) remains the same throughout the whole performance. This style of polyphonic singing, which is quite typical for zär, has been described e.g. as chordal unit polyphony (Aslanishvili, 201014). What can also be seen in the pitch trajectories in Figure 3b) is that the singers intonate with very strong sliding phases, both at the beginning and the end of the notes. This has been observed to be quite typical for Svan vocal music in general.

Yet another striking feature of the zär recording shown in Figure 3 is that the pitches rise steadily by about a whole tone (200 cents) during 140 seconds. Such a gradual rise in pitch has been observed for some of the other zär recordings discussed below (see also Figure 4 in part 2), but is also well known for other unaccompanied vocal performance traditions worldwide. Specific examples of this phenomenon are discussed for example in chapter 7 in Ambrazevičius et al., (2015). The occurrence of gradual pitch shifts is also a very strong argument against an uncritical transcription of zär into a 12-TET (12-toneequal-temperament) notation system. It does not take much fantasy to realize that the inevitable use of accidentals in connection with trying to transcribe gradual pitch shifts will be easily misinterpreted as indicating key changes.

In the context of analyzing the melodic and harmonic properties of the zär recordings in the present study, we are not interested in the very strong sliding phases at the beginning

\footnotetext{
13 Logarithmic pitch perception means that differences in frequencies are perceived as identical if the difference of the logarithms of their frequencies are identical. According to basic algebra this is equivalent to the statement that the ratio of their frequencies is identical. E.g. for the interval of a pure fifth, the frequency ratio is always $3 / 2$, independent of where in the frequency range it is measured. This is equivalent to an interval size of $1200 \cdot \log 2 \cdot(3 / 2)=702$ cents.

14 Out of consideration for the international readership, we quote, where possible, English translations or summaries, here for example of Aslanishvili (1954).
} 
and the end of notes. In particular for the determination of the tuning system, we are only interested in the stable segments of the pitch trajectories during identified note objects. Therefore, in the next step of our standard processing chain, we remove all sliding phases from the F0 trajectories by cutting off 0.15 seconds at the beginning and the end of each F0 trajectory within each note.

The result of this procedure for the three voices of the Ushgul zär is shown in Figure $4 \mathrm{a}$ ). From these 'cleaned' trajectories, new and interesting forms of visualizations of the acoustical/musical information contents can be derived, e.g. the one shown in Figure 4 b), to which we refer as harmonic melograph.

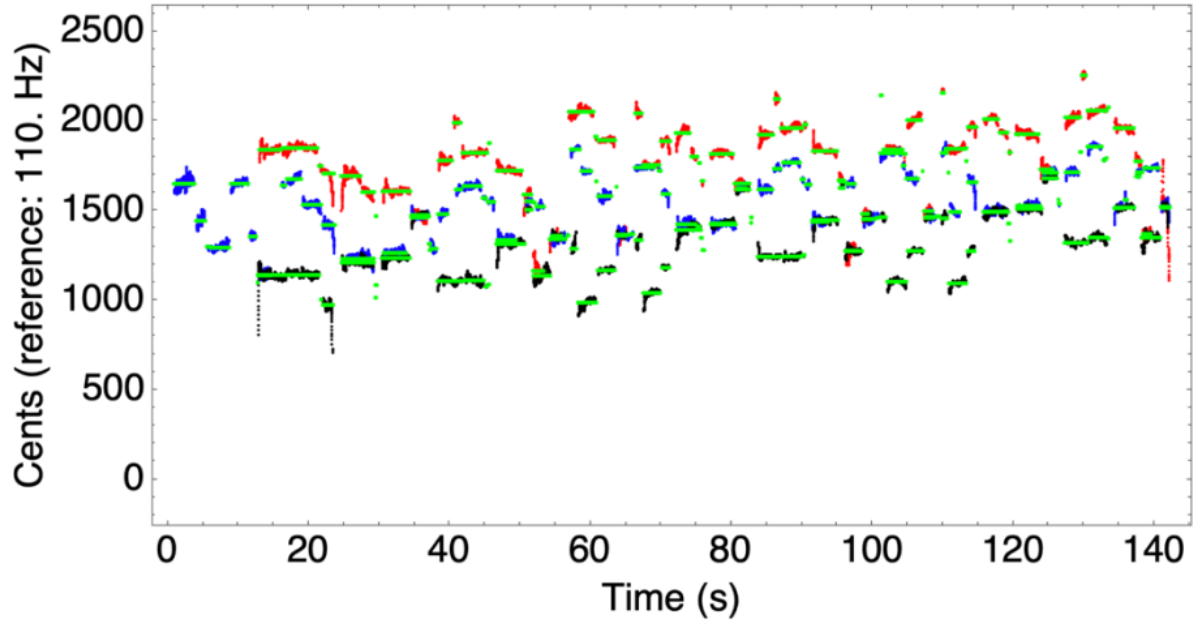

a)

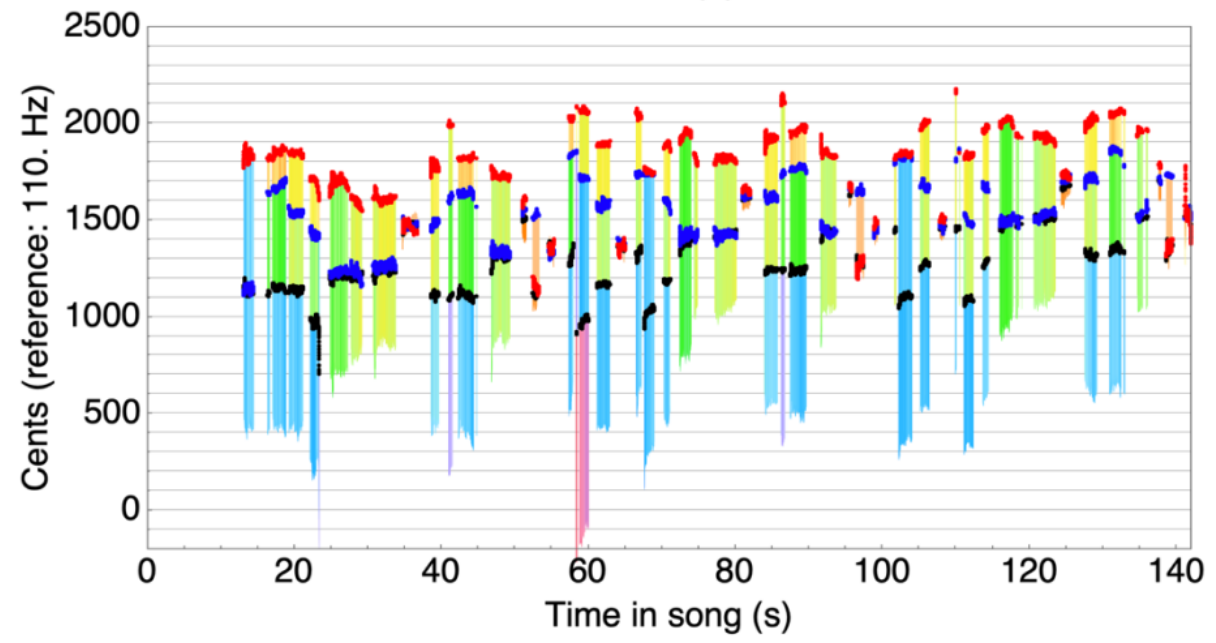

$\square 0 \square 800$

$\square 100 \square 900$

$\square 200 \square 1000$

$\square 300 \square 1100$

$\square 400 \quad 1200$

$\square 500$

$\square 600$

$\square 700$

b)

Figure 4. a) Removing the sliding phases at the beginning and the end of each note object from the F0 trajectories. b) Harmonic melograph display. The spaces between the middle and top voice and the bass and middle voice are color coded according to the corresponding harmonic interval sizes between the voices. The space below the bass voice is shaped and color coded according to the interval between bass and top voice. 
Although it may take some time to get used to, the harmonic melograph visualization in Figure $4 \mathrm{~b}$ ) is a very powerful way to display both the melodic and harmonic content of the Ushgul zär in a single plot. Since the red, blue, and black wiggly line segments show the F0 trajectories for the top, middle, and bass voice as before, they contain all the information about the melodic properties of the chant. In addition, the vertical colorcoded lines between the individual voice trajectories encode in their color the harmonic information content at any instance of time. To make this more specific, Figure 4 b) shows three dominant colors: blueish, greenish, and yellowish. As can be seen from the legend on the right, the blueish colors correspond to interval sizes of approximately 700 cents, in other words, to fifths. Hence, in one glimpse one can see that the bass and top voice move in parallel fifths for most of the chant, only interrupted by a short segment of reddish colors (approx. 1200 cents, which is equivalent to an octave) at about 60 seconds. The change between darker greenish and lighter greenish/yellowish for the intervals between the bass and the middle voice on the other hand illustrates that the harmonic interval between bass and middle voice changes between fourths (500 cents) and thirds (300-400 cents), once in a while interrupted by a short segment of fifths (700 cents). Finally, by similar reasoning, it can be seen that the interval between the middle and top voice is dominated by thirds sometimes going down to major seconds (200 cents). In other words, in a single glimpse one can see that harmonically the Ushgul zär consists of more or less parallel fifths between the bass and the top voice, and differently sized thirds and fourths between the bass and the middle voice, while the harmonic intervals between the top and middle voice is dominated by thirds.

In Figure 5 the harmonic melograph visualization is used to compare all the different realizations of zär, which we collected during the 2016 field expedition. 

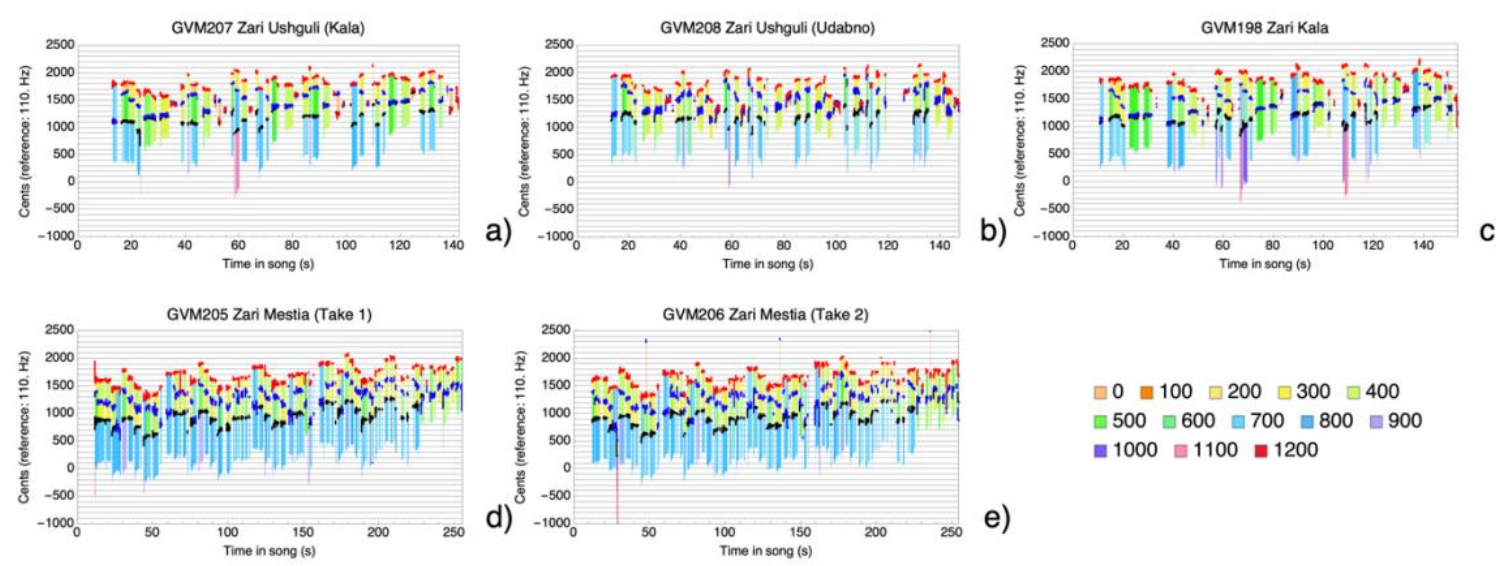

$\square 0 \square 100 \square 200 \square 300 \square 400$

$\square 500 \square 600 \square 700 \backsim 800 \square 900$

घ1000 $\square 1100 \approx 1200$
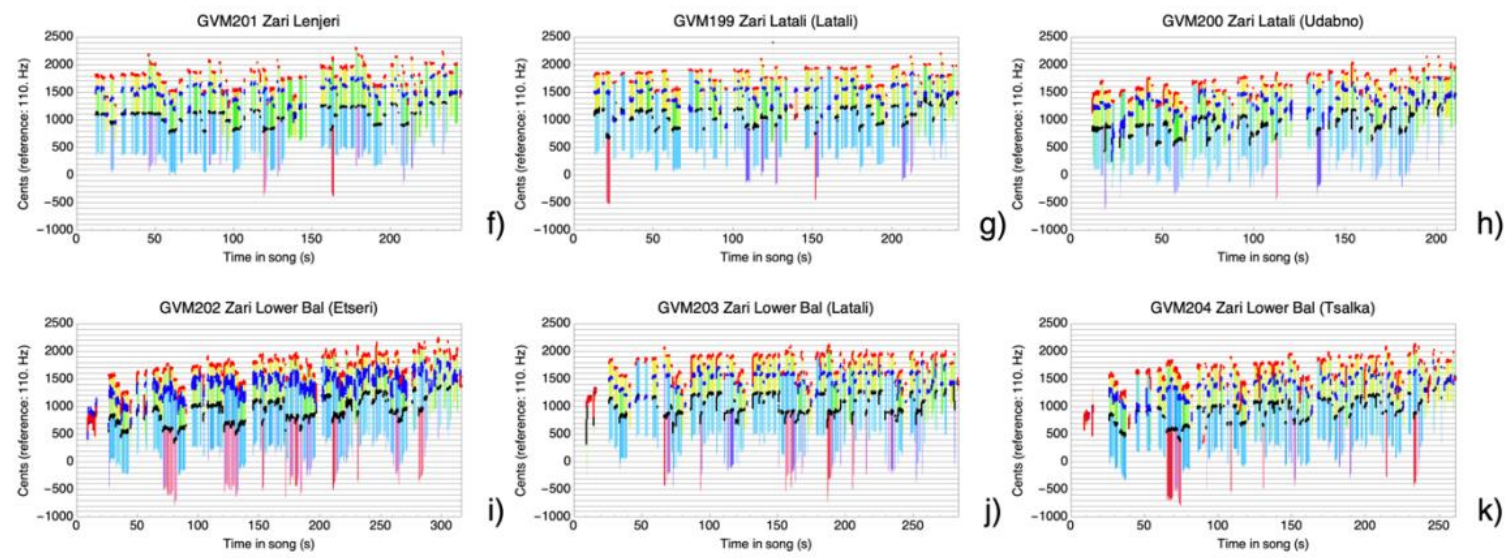

Figure 5. Joint visualization of the melodic and the harmonic content of all eleven zär recordings obtained during the 2016 field expedition. The type of visualization as harmonic melograph plot is the same as in Figure 4.

In Figure 5, the vertical position within each panel corresponds to the F0 difference in cents with respect to the chosen reference frequency of $110 \mathrm{~Hz}$. It is worth noting that the color scale used for the intervals is perceptionally linear. This means that color changes are expected to correlate approximately to the perceived pitch changes related to each interval. The purpose of Figure 5 is to graphically illustrate some systematic changes of basic musical characteristics of the different zär recordings in relation to the geographical /topographical positions of the locations of origin of the different zär. For this purpose, the individual panels in Figure 5 are arranged from a) to k) in such a way that the altitudes of the locations of origins of the zär (see Figure 1) change systematically along the course of the Enguri valley from the highest location (Ushgul at approx. 2150 $\mathrm{m}$ ) down to the lowest ones in the Lower Bal region. Interestingly, this correlates with a systematic change of some basic musical properties of the zär. First, it can be seen that the ambitus of the zär systematically increases from the top to the bottom panels. At the same time, judged simply by the increased complexity of the visual images, the musical 
structure of the zär becomes more 'complex'. For example, the Lower Bal variant of $z a ̈ r$ no longer consists only of parallel fifths between the bass and the top voice, which persist for the whole chant, but the reddish colors indicate several segments in which this interval increases in size up to an octave. This behavior seems to be indicated already in the Lat'li zär. Two other aspects are worth mentioning at this point. First, it can be seen that some zärs show a very pronounced gradual rise in pitch, while some do not. Secondly, caused by the heavy rain during the first recording (Take 1) of the Mest'ia zär shown in Figure 5 c), only larynx microphones were used. However, because of the strong emotional impression which this performance had on us, we decided, even under the risk of water damage of the very delicate headset equipment, to rerecord the performance with full equipment. To our surprise, the pitch trajectories of two 4-minute-long recordings are nearly identical. In particular, although the steepness of the gradual pitch rise in both cases is slightly different, the ending F0 values are essentially identical in both cases. Furthermore, this demonstrates, in contrast to what one could suspect as a naive listener of $z a ̈ r$, that it does not contain strong improvisational elements. This naturally raises the question how a zär is actually learned? Our informants told us that zär cannot be taught or learned but that one has "to grow up with it".

In the context of music perception, it has been suggested to distinguish between the sequential (horizontal, melodic) and the concomitant (vertical, harmonic) structure (Nikolsky, 2015). For zär, the harmonic aspect is perceptionally clearly dominant, as can easily be checked by listening to the recordings ${ }^{15}$ or by simply considering how long the individual notes are perceived (e. g. Figures 3 and 4). In order to analyze the harmonic content, we have determined all concomitant pitches in all three voices, and from them determined all the jointly perceived intervals. Their frequencies are shown as gray shaded histograms in Figure 6.

${ }^{15}$ https://www.audiolabs-erlangen.de/resources/MIR/2017-GeorgianMusic-Scherbaum. 

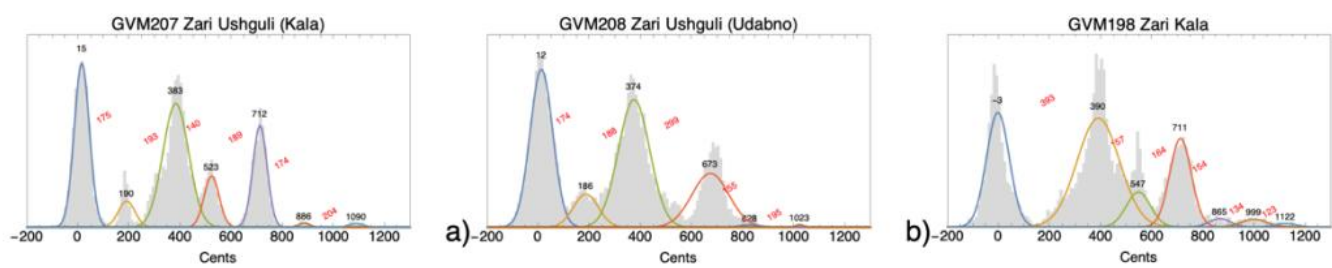

c)
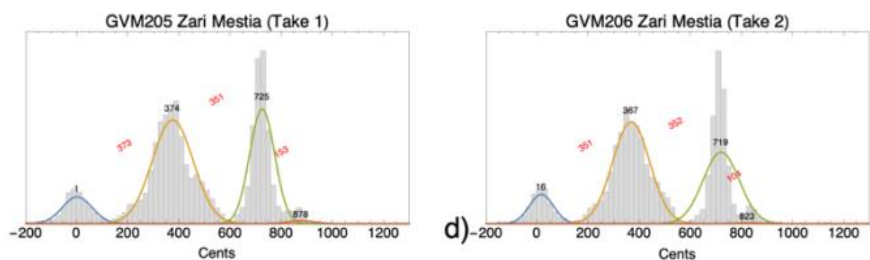

e)
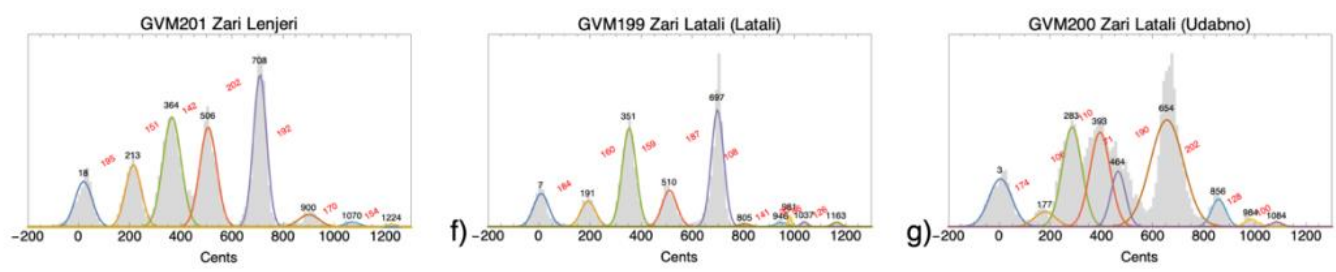

h)
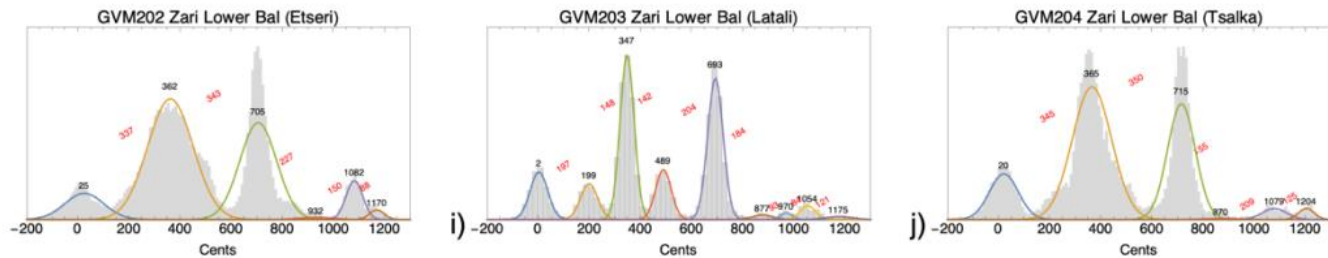

k)

Figure 6. Harmonic interval frequency histograms for all concomitant pitches in the pitch trajectories of all zär realisations ${ }^{16}$. The black numbers correspond to the mean sizes $\left(\mu_{k}\right)$ for each interval group in cents while the tilted red numbers represent the differences between the interval groups in cents.

As we can see, intervals appear more or less strongly clustered. This justifies trying to model them as Gaussian Mixture Models (GMMs), which are simply weighted mixtures of individual Gaussian distributions $\mathcal{N}\left(\mu, \sigma^{2}\right)$, each of which is defined by a mean value $\mu$ and a standard deviation $\sigma$ (Frühwirth-Schnatter, 2006). For the case of K interval groups, this results in a representation as $\sum_{k=1}^{K} w_{k} \mathcal{N}\left(\mu_{k}, \sigma_{k}^{2}\right)$, which corresponds to the smooth bell-shaped curves in Figure 6. Table 1 displays the mean values and standard deviations for the GMMs of the harmonic intervals for all zär realizations.

16 The panel to the right of panel e) was left empty on purpose. This way, the sequence of rows from top to bottom more systematicall reflects the change of the geographical locations of the origins of the zär from Ushgul to Lower Bal. 


\begin{tabular}{|c|c|c|c|c|c|c|c|c|c|c|c|}
\hline GVM207 & $15 \pm 30$ & $190 \pm 33$ & & $383 \pm 50$ & & $523 \pm 29$ & $712 \pm 28$ & $886 \pm 22$ & & $1090 \pm 28$ & \\
\hline GVM208 & $12 \pm 44$ & $186 \pm 49$ & & $374 \pm 61$ & & & $673 \pm 72$ & $828 \pm 40$ & & $1023 \pm 14$ & \\
\hline GVM198 & $-3 \pm 44$ & & & $390 \pm 83$ & & $547 \pm 47$ & $711 \pm 42$ & $865 \pm 40$ & & $999 \pm 48$ & $1122 \pm 40$ \\
\hline GVM205 & $1 \pm 58$ & & & $374 \pm 80$ & & & $725 \pm 49$ & $878 \pm 50$ & & & \\
\hline GVM206 & $15 \pm 42$ & & & $369 \pm 71$ & & & $717 \pm 38$ & $845 \pm 38$ & & & \\
\hline GVM201 & $18 \pm 34$ & $213 \pm 31$ & & $364 \pm 36$ & & $506 \pm 33$ & $708 \pm 26$ & $900 \pm 40$ & & $1070 \pm 29$ & $1224 \pm 18$ \\
\hline GVM199 & $7 \pm 29$ & $191 \pm 28$ & & $351 \pm 27$ & & $509 \pm 29$ & $699 \pm 27$ & & $960 \pm 54$ & $1038 \pm 13$ & $1164 \pm 15$ \\
\hline GVM200 & $3 \pm 44$ & $177 \pm 41$ & $283 \pm 38$ & & $393 \pm 40$ & $464 \pm 29$ & $654 \pm 64$ & $859 \pm 28$ & $984 \pm 24$ & $1084 \pm 22$ & \\
\hline GVM202 & $25 \pm 76$ & & & $362 \pm 89$ & & & $705 \pm 72$ & & $932 \pm 64$ & $1082 \pm 33$ & $1170 \pm 28$ \\
\hline GVM203 & $2 \pm 34$ & $199 \pm 33$ & & $347 \pm 27$ & & $489 \pm 30$ & $693 \pm 30$ & $877 \pm 40$ & $970 \pm 24$ & $1054 \pm 30$ & $1175 \pm 52$ \\
\hline GVM204 & $20 \pm 57$ & & & $365 \pm 77$ & & & $715 \pm 54$ & $870 \pm 73$ & & $1079 \pm 47$ & $1204 \pm 30$ \\
\hline
\end{tabular}

Table 1. Mean values and standard deviations, written as $\mu_{k} \pm \sigma_{\mathrm{k}}$, for the GMMs of the harmonic intervals for all zär realizations.

The mean values of the individual Gaussians (the $\mu_{k}$ ) correspond to the center values of the individual interval groups. They are assumed to define the interval sizes which (on average) would be perceived, while the standard deviations (the $\sigma_{\mathrm{k}}$ ) define the variability within the associated interval group. The larger the area under an individual bell-shaped curve (Gaussian), the more often the corresponding interval group is repeated in the complete zär. Because repetition of pitches increases their anchorage in memory, Figure 6 together with Table 1 represent the harmonic content in a simple, but perceptionally meaningful way, without having to make any further assumptions (Deutsch, 1972; 1975).

As can be seen in Figure 6, overall, the three most salient harmonic interval groups (the ones with the largest areas under their bell-shaped curves) are thirds (with central values $\mu_{k}$ between 350 and 400 cents), unison ( $\mu_{k}$ close to 0 cents), and fifths ( $\mu_{k}$ around 700 cents). In some realizations (e. g. for GVM-IDs 199, 201, 203, and 207) harmonic fourths ( $\mu_{k}$ close to 500 cents) also appear as distinct interval group, while in others they are barely apparent (e. g. for GVM-ID 208) or appear as merged with the thirds (e.g. for GVMIDs 200, 202, 204, 205, 206). A similar observation can be made for major seconds (around 200 cents), which appear only in a subset of the zär realizations. Overall, the harmonic interval inventory used seems to strongly depend on the ensemble and less on the location of origin of the zär (cf. Figure 6 and Table 1). For example, in the realization of the Ushgul zär by the singers from Udabno (GVM-ID 208), the singers use a different harmonic interval inventory than the singers from Ushgul (GVM-ID 207). When singing the Lat'li zär (GVM-ID 200), the singers from Udabno also use a different harmonic interval inventory than the singers from Lat'li (GVM-ID 199). 


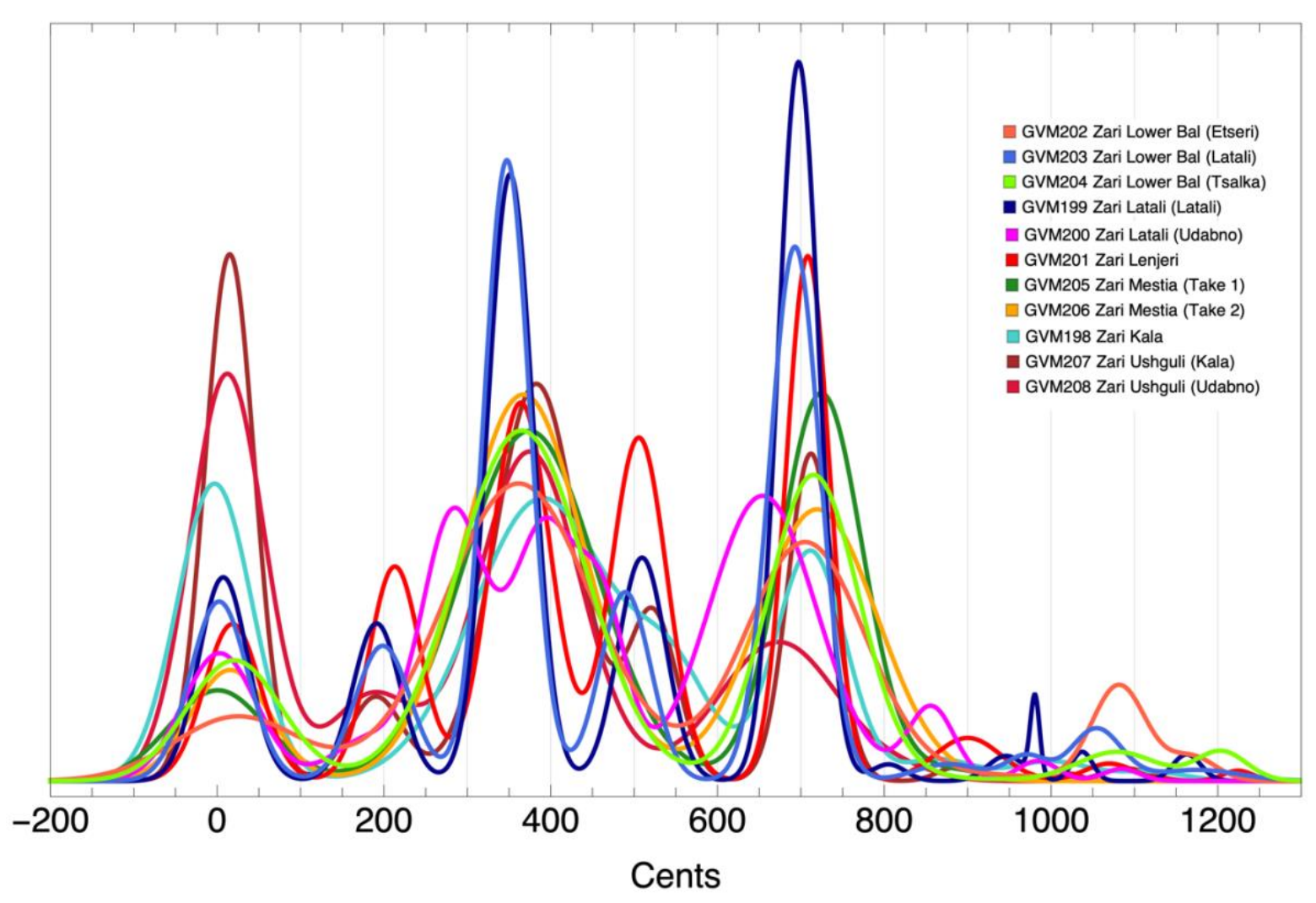

Figure 7. Superposition of all the Gaussian Mixture Models for the harmonic interval distributions of the different zär realisations shown in Figure 6.

Of particular interest in this case are the properties of the harmonic interval inventory of the Udabno singers regarding harmonic thirds. This can be seen especially well in Figure 7, where all the Gaussian mixture distributions for all realizations of zär are superimposed in a single plot. Figure 7 shows that for most of the interval groups, the central values of the individual Gaussians (the $\mu_{k}$ ) deviate, but not very much, from each other. Except for the Lat'li zär, sung by the Udabno singers (GVM-ID 200, magenta curve), thirds are never minor or major (300 or 400 cents), but distributed around an intermediate value (approximately around 350 cents). This recording is also special in that most of the harmonic fifths are flat (less than 500 cents), and their values scatter widely $\left(\sigma_{\mathrm{k}}=76\right.$ cents; Table 1$)$.

In order to better understand this behavior, but also to provide yet another perspective on the harmonic tuning systems used in the different zär realizations, Figure 8 shows how the harmonic intervals evolve as a function of time. This is done for all three voice combinations, which are differently color coded. 

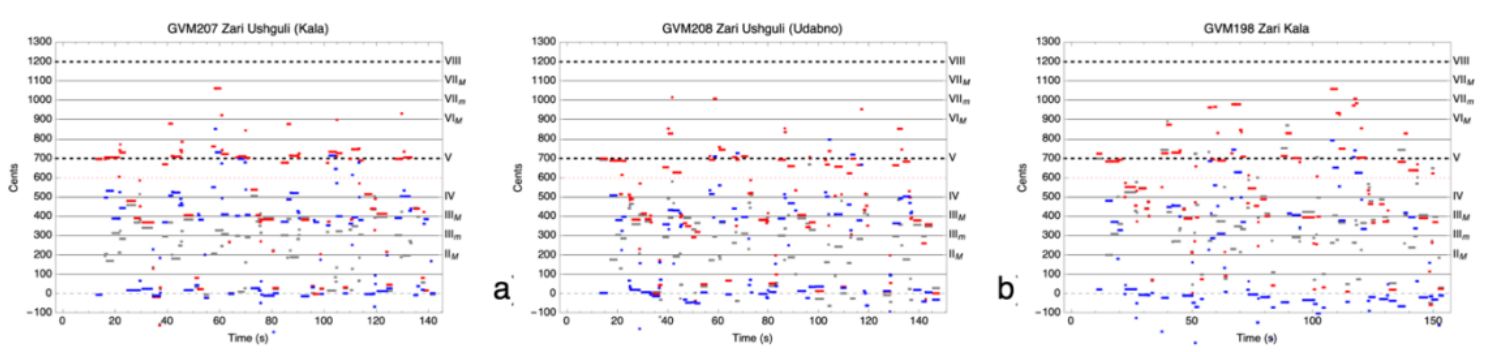

c)
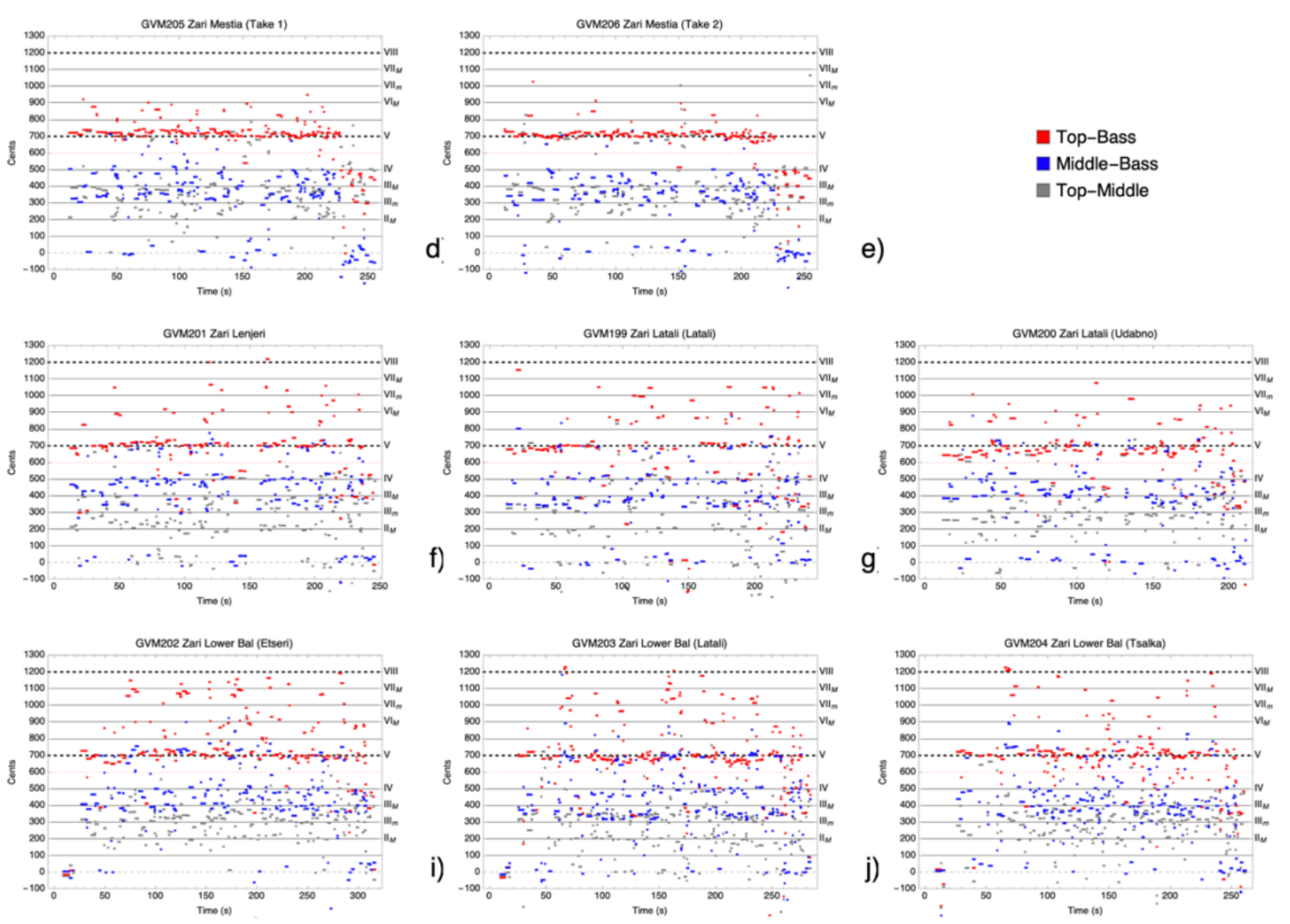

Figure 8. Harmonic interval structure in all zär recordings as a function of time. The different color codes indicate different voice combinations.

Figure 8h) illustrates that the 'minor thirds' in the harmonic interval inventory of the Lat'li zär sung by the Udabno singers (GVM-ID 200) appear predominantly between the top and the middle voice (gray color), while the 'major thirds' appear between the middle and the bass voice (blue color). Furthermore, the flat fifths appear predominantly between the top and the bass voice (red color). All Udabno singers of the Lat'li zär were originally from Lat'li and had moved to Udabno during the 1980s. A flattened fifth between top and the bass voice, although not as strong as in the case of GVM-ID 200, is also visible in the recording of the Ushgul zär, sung by the Udabno singers (Figure 8b). The top and bass voice singers in both realizations are the same, while the middle voice singer in case of the Ushgul zär was from K'àl, not far from Ushgul (see Figure 1). 
Figures $6-8$ provide different perspectives on the harmonic part of the tonal organization represented in the different zär recordings. Regarding the melodic tuning system, we face the challenge having to correct the pitch trajectories for the gradual pitch rise present in some of the recordings, e.g. in our running example GVM-ID 207, shown in Figure 3. The way we do this is illustrated in Figure 9.

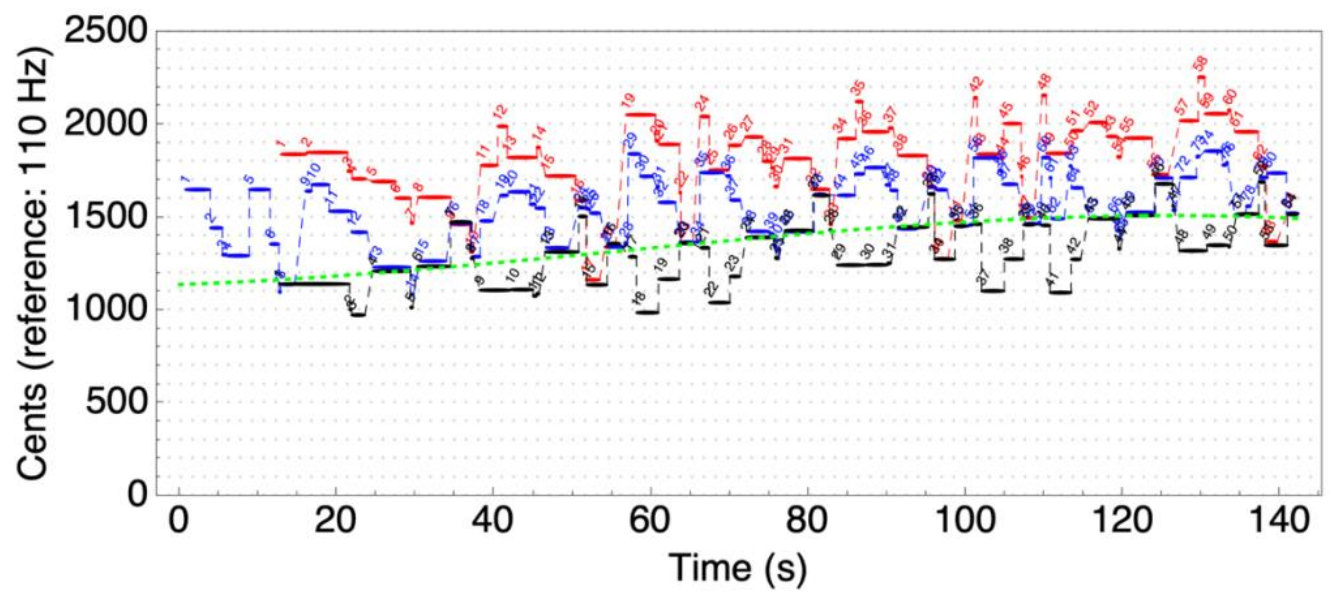

a)

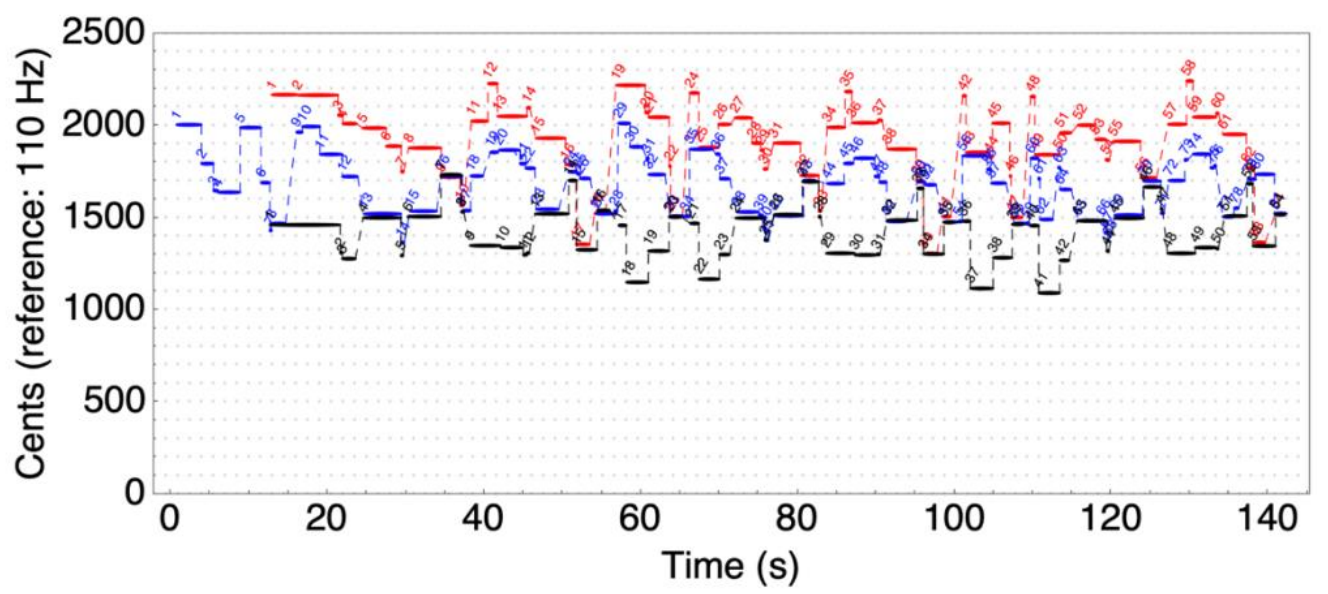

b)

Figure 9. a) Note tracks for the three voices of the Ushgul zär (GVM-ID 207). The green line corresponds to correction curve for the pitch drift. b) Pitch-drift corrected note tracks.

Since visually the pitch drift can be easily identified in the note tracks, we first produce a plot of the note tracks, in which the note text is replaced by the note number (running from 1 to the total number of notes). Subsequently, we identify the sequence of notes in one of the voices, which we believe best represents the gradual pitch drift by a small number of samples. Finally, a regression curve (a third-degree polynomial) is calculated, which passes through the selected notes, and which then quantifies the pitch drift in a functional form. This is the green line shown in Figure 9a). This functional form is then used to correct all the pitches in the raw F0 values and note trajectories, so that the 
gradual pitch drift is removed from the resulting trajectories (Figure 9b). In order to facilitate the visual comparison of the pitch inventories of the different recordings, we also shift all the F0 values by a constant amount (which differs for each zär) in such a way that the pitch group, which contains the final long note (with a duration of at least 1 sec) in the middle voice, has a center F0 value of 1500 cents. Figure 10 shows the resulting note tracks for all pitch-drift corrected zär realizations.
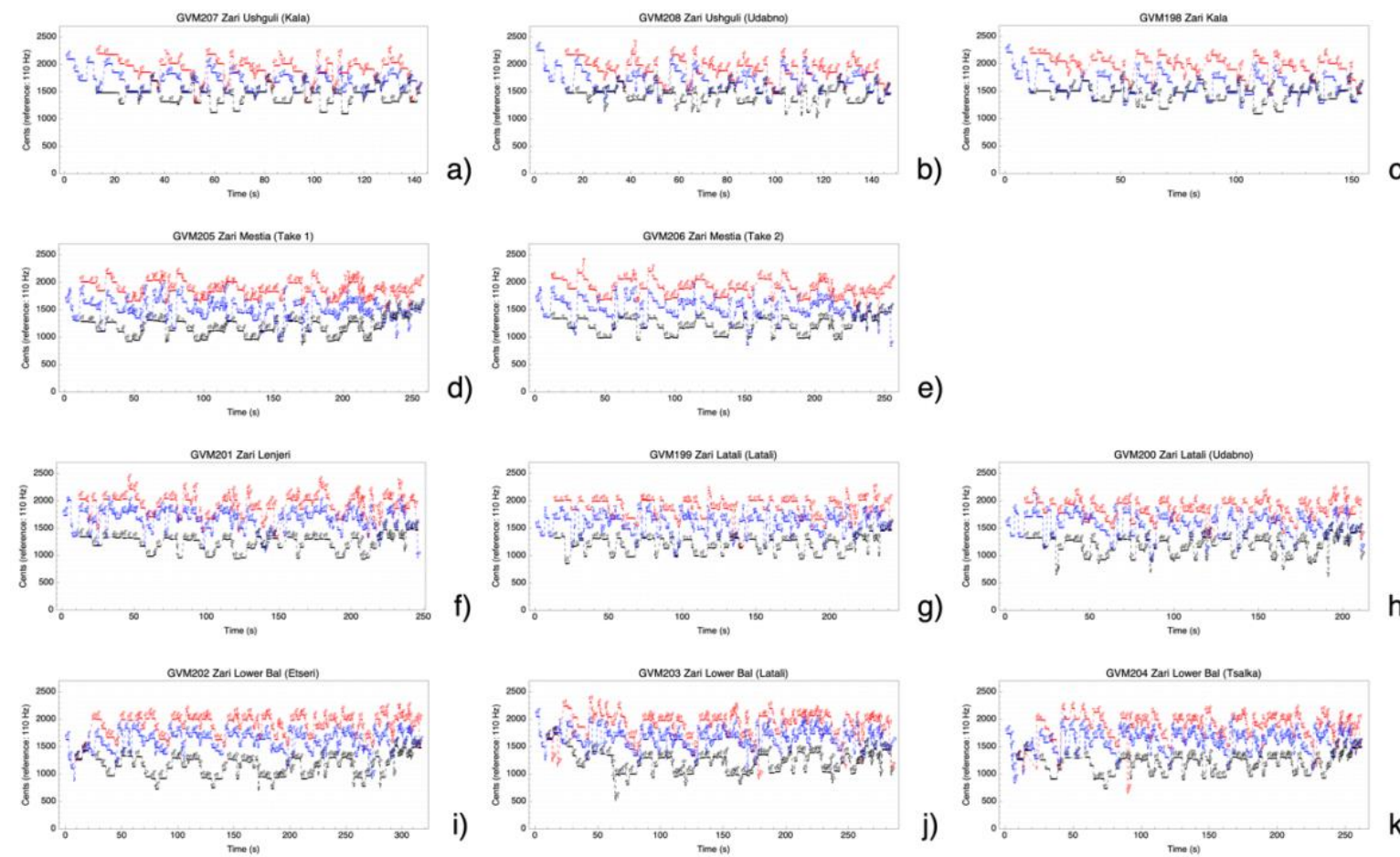

Figure 10. Pitch-shift corrected note tracks for all zär realizations.

Subsequently, we calculate F0 histograms from the pitch-drift corrected cleaned pitch trajectories and model them as Gaussian Mixture Models (GMM), as we did for the interval distributions. The results are shown in Figure 11 and Table 2. 

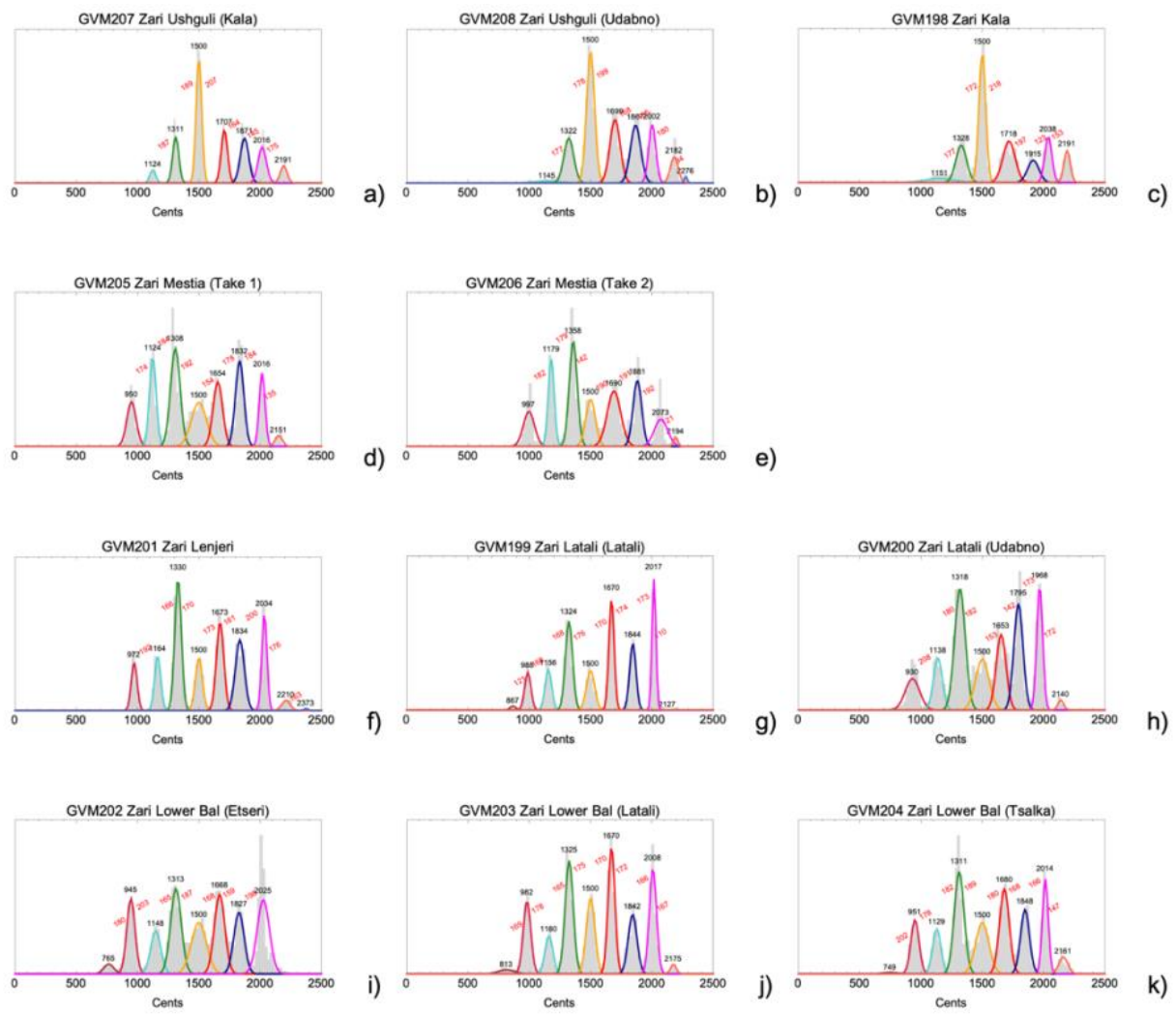

Figure 11. F0 value histograms and corresponding Gaussian Mixture distributions calculated from the pitch-drift corrected pitch trajectories of all zär realizations.

\begin{tabular}{|c|c|c|c|c|c|c|c|c|c|c|}
\hline GVM207 & & & $1126 \pm 33$ & $1318 \pm 30$ & $1500 \pm 29$ & $1710 \pm 38$ & $1872 \pm 38$ & $2008 \pm 34$ & $2186 \pm 32$ & \\
\hline GVM208 & & & $1145 \pm 116$ & $1322 \pm 40$ & $1500 \pm 33$ & $1699 \pm 42$ & $1867 \pm 42$ & $2002 \pm 29$ & $2182 \pm 31$ & $2276 \pm 11$ \\
\hline GVM198 & & & $1151 \pm 121$ & $1328 \pm 44$ & $1500 \pm 27$ & $1718 \pm 50$ & $1915 \pm 47$ & $2038 \pm 29$ & $2191 \pm 26$ & \\
\hline GVM205 & & $952 \pm 38$ & $1126 \pm 27$ & $1309 \pm 38$ & $1500 \pm 61$ & $1656 \pm 39$ & $1834 \pm 33$ & $2017 \pm 24$ & $2153 \pm 30$ & \\
\hline GVM206 & & $1000 \pm 37$ & $1179 \pm 23$ & $1358 \pm 29$ & $1500 \pm 37$ & $1701 \pm 52$ & $1887 \pm 32$ & $2067 \pm 23$ & $2189 \pm 19$ & \\
\hline GVM201 & & $972 \pm 24$ & $1164 \pm 25$ & $1330 \pm 27$ & $1500 \pm 28$ & $1673 \pm 30$ & $1834 \pm 36$ & $2034 \pm 21$ & $2210 \pm 34$ & $2373 \pm 15$ \\
\hline GVM199 & $867 \pm 25$ & $988 \pm 25$ & $1156 \pm 27$ & $1324 \pm 29$ & $1500 \pm 34$ & $1670 \pm 21$ & $1844 \pm 26$ & $2017 \pm 16$ & $2127 \pm 233$ & \\
\hline GVM200 & & $930 \pm 59$ & $1138 \pm 36$ & $1318 \pm 43$ & $1500 \pm 55$ & $1653 \pm 40$ & $1795 \pm 37$ & $1968 \pm 24$ & $2140 \pm 23$ & \\
\hline GVM202 & $765 \pm 40$ & $945 \pm 34$ & $1148 \pm 41$ & $1313 \pm 43$ & $1500 \pm 61$ & $1668 \pm 42$ & $1827 \pm 42$ & $2025 \pm 50$ & & \\
\hline GVM203 & $813 \pm 68$ & $982 \pm 30$ & $1160 \pm 32$ & $1325 \pm 33$ & $1500 \pm 35$ & $1670 \pm 27$ & $1842 \pm 35$ & $2008 \pm 28$ & $2175 \pm 23$ & \\
\hline GVM204 & $749 \pm 70$ & $951 \pm 33$ & $1129 \pm 33$ & $1311 \pm 39$ & $1500 \pm 53$ & $1680 \pm 39$ & $1848 \pm 36$ & $2014 \pm 24$ & $2161 \pm 36$ & \\
\hline Mean & 799 & 964 & 1147 & 3122 & 1500 & 1680 & 1851 & 2019 & 2172 & 2324 \\
\hline
\end{tabular}

Table 2. Mean values and standard deviations, written as $\mu_{k} \pm \sigma_{\mathrm{k}}$, for the GMMs of shown in Figure 10. 
In a situation without a temporal pitch drift, Figure 10 would represent the melodic tuning system, or, in other words, the structure of the scale. In the present situation, however, this interpretation has to be considered very carefully because it depends strongly on a) how well the pitch-drift correction works and b) if the concept of a melodic scale is appropriate at all for zär (or other situations with gradual pitch shifts). Nevertheless, Figure 10 and Table 2 reveal some interesting properties which, similar to the harmonic interval distributions shown in Figures 6 and 7, show a systematic correlation with the altitude of the locations of origin of the different zär.

For the zär from Ushgul and K'āl, the note group containing the final note (shown in orange in Figure 10) corresponds to the third-lowest mode degree, while for the Lower Bal variants it becomes the central mode degree. In addition, the ambitus of the zär increase more or less systematically from Figure 10 a) to k).

Finally, as the last aspect of the tonal organization, we determined the histograms of the melodic step sizes for all the zär representation (Figure 12). They show that the melodic progressions in all zär variants happen mostly in single steps, and only rarely in jumps (thirds, and sometimes fourths and fifths). The step sizes of the single steps are not constant, however, but rather, fluctuating between 150 and 180 cents. Similar values have been observed for a dataset of Georgian liturgical chants sung by the master chanter Artem Erkomaishvili (Scherbaum et al., 2020). 

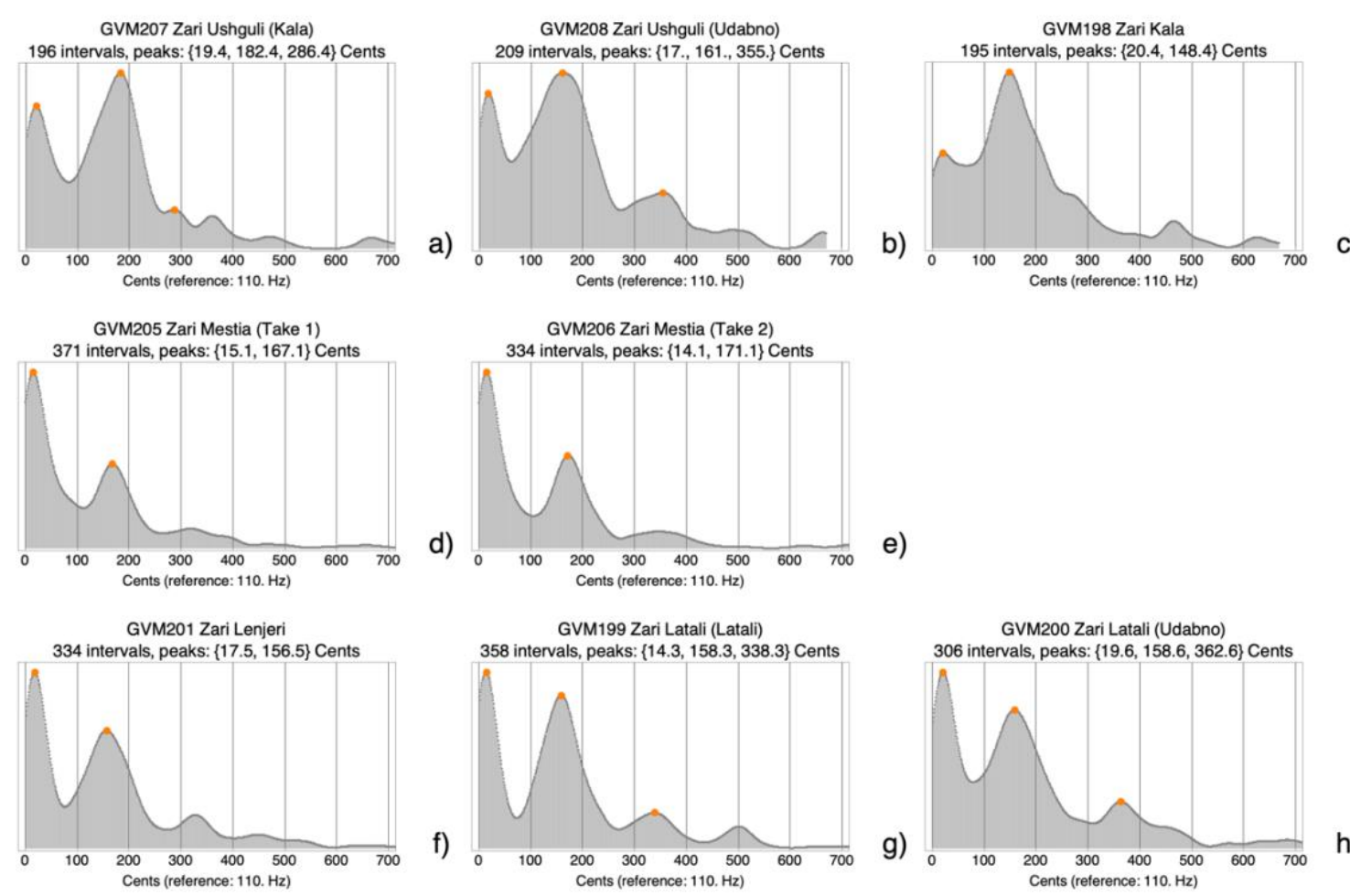

e)
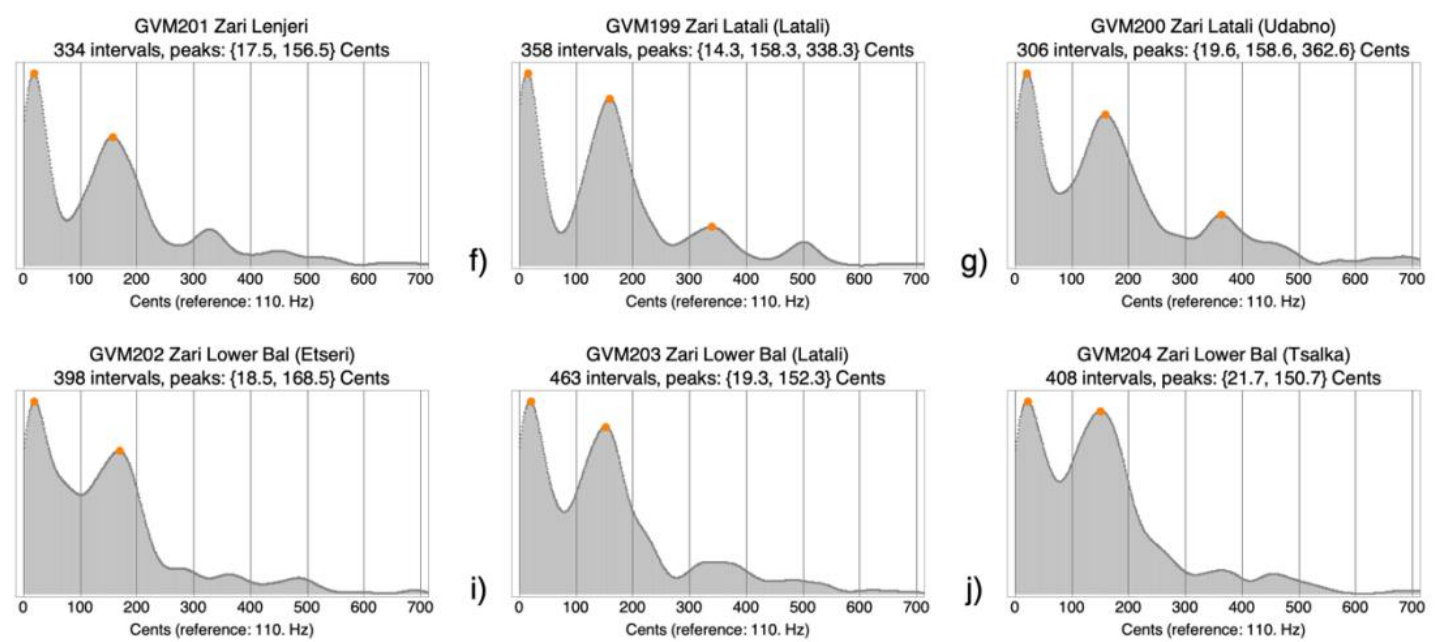

h)
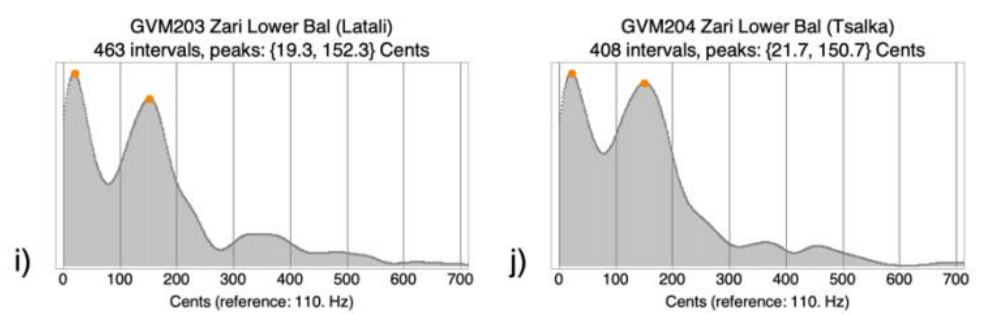

Figure 12. Melodic step size histograms for all recorded zär realizations.

\section{Discussion}

In this part of our study, we have analyzed the harmonic and melodic tuning systems of eleven different performances of six different variants of zär, performed by singers from different Svan villages. For all eleven recordings, the joint visualization of their melodic and harmonic content as harmonic melograph plots shows that the bass and the top voice predominantly move in parallel harmonic fifths. One of the most interesting results of our analysis is the observation that the musical structure of zär, expressed for example in its ambitus, the complexity of its melodic progression, and its harmonic chord inventory, change systematically along the course of the Enguri valley. In the upper course of the river (between Ushjgul and Mest'ia) the durations of zär are rather short, with little diversity in the harmonic inventory, and the harmonic interval between the bass voice and the top voice rarely exceeds a fifth. In contrast, the durations of the Lower Bal variant 
of zär increases significantly (roughly a factor of 2), the harmonic inventory becomes much more diverse, and the ambitus reaches an octave and more. The intra-variant differences of the musical properties for different groups of singers were observed to be remarkably different. This includes the use of significantly different harmonic tuning systems and strong gradual pitch rises of up to 100 cents per minute, which are maintained for the complete duration of a chant. In other words, the properties of the tonal organization observed in the recorded performances depend more on who performs a particular variant than the zär variant itself. The observation that the two subsequent performances of the Mest'ia variant of zär by a group of singers recorded in Zargăsh were essentially identical demonstrates the complete absence of personal improvisational elements in these two performances. We interpret this observation together with the absence of any-at least for non-ethnophores-obvious textual, melodic or rhythmic mnemonic anchors in zär as a sign that the singers recall zär from their longterm memory.

\section{Acknowledgements}

This work was supported by the German Research Foundation within the framework of the project "Computational Analysis of Traditional Georgian Vocal Music (GVM)" (DFG MU 2686/13-1, SCHE 280/20-1). First and foremost, our gratitude goes to all the people during the 2016 field expedition who allowed us to be part of and record their rituals. We are thankful to Meinard Müller and his team for the stimulating collaboration as well as for hosting the web-based repository of the GVM data. We would like to thank Nino Sadradze for providing the GIS shape files for Svaneti and Susanne Ziegler and Simha Arom for their comments on the manuscript.

\section{REFERENCES}

Akhobadze, Vladimer. (1957). Kartuli Khalkhuri Simgherebis k'rebuli [Collection of Georgian Folk Songs]. Tbilisi: T’eknik'a da shroma.

Ambrazevičius, Rytis; Budrys, Robertas and Viśnievska, Irena. (2015). Scales in Lithuanian Traditional Music: Acoustics, Cognition, and Contexts. Kaunas: Kaunas University of Technology. 
Arakishvili, Dimitri. (1950). Svanuri Khalkhuri Simgherebi [Svan Folk Songs]. Tbilisi: Khelovneba.

Aslanishvili, Shalva. (2010). "Forms of Multipart Singing in Georgian Folk Songs." Echoes from Georgia: Seventeen Arguments on Georgian Polyphony, Ed. Tsurtsumia, Rusudan and Joseph Jordania: pp. 57-81. Nova Science Publishers, Inc.

Aslanishvili, Shalva. (1954). Narkvevebi Kartuli Khalkhuri Simgherebis Shesakheb [Essays on Georgian Folk Songs]. Vol. I (in Georgian). Tbilisi: Khelovneba.

Azikuri, Nanuli. (2002). Khmit Nat'irlebi [Lamentation with Voice]. Tbilisi: Kavkasiuri sakhli.

Bolle Zemp, Sylvie. (2001). "Khmovnebi Da Akordebi. Simghera Zemo Svanetshi” [Vowels and Chords. Singing in Zemo Svaneti]. Sasuliero Da Saero Musikis Mravalkhmianobis Problemebi [Problems of Polyphony in Sacred and Secular Music], Ed. Tsurtsumia, Rusudan: pp. 292-303. Tbilisi: Tbilisi State Conservatoire.

Bolle Zemp, Sylvie. (1997). "Mehrstimmige Wehrufe? Ein Begräbnisgesang Aus Swanetien." [Multi-Voiced Laments? A Funeral Chant From Svaneti]. Georgica: 134-148.

Dadwani, Platon. (1973). "Svanetis Chveulebani" [Customs of Svaneti]. Etnograpiuli Ts'erilebi Svanetze [Ethnographic Records on Svaneti]. Tbilisi: Sabch'ota Sakartvelo: 746.

Deutsch, Diana. (1972). "Effect of Repetition of Standard and Comparison Tones on Recognition Memory for Pitch". Journal of Experimental Psychology. 93: 156-62.

Deutsch, Diana. (1975). "The Organization of Short-Term Memory for a Single Acoustic Attribute." Short-Term Memory, Eds. Deutsch, Diana and J. A. Deutsch: 107-51. New York, NY: Academic Press.

Dirr, Adolf. (1914). “Neunzehn Swanische Lieder (Statt Eines Referates.)”. Anthropos, 9 (3/4): 597-621.

Ellis, Alexander J. (1885). “On the Musical Scales of Various Nations.” Journal of the Society of Arts. 33: 485. 
Firth, Raymond; Mclean, Mervyn. (2006). Tikopia Songs. Poetic and Musica Art of a Polypnesian People of the Solomon Islands. Cambridge: Cambridge University Press.

Frühwirth-Schnatter, Sylvia. (2006). Finite Mixture and Markov Switching Models. Springer Science+Business Media, LLC.

Gabisonia, Tamaz. (2012). “Krist'ianuli K'vali Svanur Himnur Simgherebshi” [Christian Traces in Svan Hymn Songs] Archaic Elements in the Ethnic Culture of Highland Georgia. http://eprints.iliauni.edu.ge/id/eprint/9207.

Gogotishvili, Vladimer. (1994). “Svanuri Sagundo Mravalkhmianobis Pakt'uruli Taviseburebebis Sak'itkhisatvis" [On the Issue of Structural Peculiarities of Svan Choral Polyphony]. Issues of Musicology. Scientific Works, Ed. Tsurtsumia, Rusudan: pp. 3-39. Tbilisi: Tbilisi State Conservatiore.

Goltsev, Viktor. (1933). Savane: Zapisi o Verkhney Svanetii [Savane: Гольцев, Виктор. Саване: Записи о Верхней Сванетии]. Moscow: Moskovskoe Tovarishschestvo Pisateley.

Graham, Laura. (1984). "Semanticity and Melody: Parameters of Contrast in Shavante Vocal Expression". Latin American Music Review / Revista de Música Latinoamericana. 5 (2): 161-85. https://www.jstor.org/stable/780071.

Jordania, Joseph. (2006). Who Asked the First Question? The Origins of Human Choral Singings, Intelligence, Language and Speech. Tbilisi: Tbilisi State University Press.

Kalandadze-Makharadze, Nino. (2005). “Glovis Zari Kartvel Mamakatsta Traditsiul Mravalkhmianobashi" [The Funeral Zari in Traditional Male Polyphony]. [The Second International Symposium on Traditional Polyphony]. Eds. Tsurtsumia, Rusudan; Jordania, Joseph: pp. 66-78. International Research Center for Traditional Polyphony of Tbilisi State Conservatoire (in Georgian and English).

Kondi, Bledar. (2012). Death and Ritual Crying: An Anthropological Approach to Albanian Funeral Customs. Berlin: Logos

Lloyd, Albert L. (1980). "Lament". The New Grove Dictionary of Music and Musicians. Vol.10. London: Macmillan. 
Love, Jakob W, and Adrienne Kaeppler. (2017). "Australia and the Pacific Islands.” The Garland Encyclopedia of World https://books.google.de/books?id=HB03DwAAQBAI\&printsec=frontcover\&dq=The+Ga rland+Encyclopedia + of + World+Music: + Australia+and+the+Pacific+Islands\&hl=en\&sa= $\underline{X \& v e d=2 a h U K E w j 3 w 0 H s 5 Y b r A h V Z I M U K H T 3 Z A E c Q 6 A E w A X o E C A U Q A g \# v=o n e p a g e \& q ~}$ =The.

Mauch, Matthias; Cannam, Chris; Bittner, Rachel; Fazekas, George; Salamon, Justin; Dai, Jiajie; Bello, Juan and Dixon, Simon. (2015). “Computer-Aided Melody Note Transcription Using the Tony Software: Accuracy and Efficiency." The First International Conference on Technologies for Music Notation and Representation, 8. https://code.soundsoftware.ac.uk/projects/tony/.

Mzhavanadze, Nana. (2018). Svanuri Sak'ult'o Rit'ualis Musik'ologiur-Antrop'ologiuri Asp'ekt'ebi [Musicological and Anthropological Aspects of Svan Sacred Ritual]. Ilia State University.

https://drive.google.com/file/d/1-Q1-1a7SWLHKJrW2 XaAWVC4dvl6zPLH/view.

Mzhavanadze, Nana, and Frank Scherbaum. (2020). "Svan Funeral Dirges (Zär): Musicological Analysis." Musicologist. 4(2): 168-197

Nikolsky, Aleksey. (2015). "Evolution of Tonal Organization in Music Mirrors Symbolic Representation of Perceptual Reality. Part-1: Prehistoric." Frontiers in Psychology 6 (OCT): 1-36. https://doi.org/10.3389/fpsyg.2015.01405.

Paliashvili, Zakaria. (1909). Kartuli Khalkhuri Simgherebis K'rebuli. Imeruli, Guruli, Rachuli, Svanuri Da Kartl-K'akhuri [Collection of Georgian Folk Songs: Imeretian, Gurian, Rach'an, Svan and Kartl-K'akhetian]. Tbilisi: Tpilisis Kartuli Pilarmoniuli Sazogadoeba N5.

Phillips-Wolley, Clive. (1883). Savage Svanetia. Vol. II. London: R. Bentley.

Rosebashvili, Kakhi. (1982). "Kartuli Khalkhuri Simgheris Svanuri Dialekti: Zogierti Sats'eso Da Rit'ualuri Simgheris Gankhilva" [Svan Dialect of Georgian Folk Song: Discussion of Some Ritual and Ritual Songs] (Annual Paper). Tbilisi: Tbilisi State Conservatoire. 
Scherbaum, Frank. (2016). "On the Benefit of Larynx-Microphone Field Recordings for the Documentation and Analysis of Polyphonic Vocal Music." [The 6th International Workshop Folk Music Analysis]. (pp. 80-87). Dublin/Ireland.

Scherbaum, Frank; Loos, Wolfgang; Kane, Frank and Vollmer; Daniel. (2015). "Body Vibrations as Source of Information for the Analysis of Polyphonic Vocal Music". [The 5th International Workshop on Folk Music Analysis]. (pp. 89-93). University Pierre and Marie Curie, Paris, France.

Scherbaum, Frank; Mzhavanadze, Nana. (2018). "A New Archive of MultichannelMultimedia Field Recordings of Traditional Georgian Singing, Praying, and Lamenting with Special Emphasis on Svaneti." LaZAR-Database. Https://Lazardb.Gbv.de/.

Scherbaum, Frank; Mzhavanadze, Nana; Rosenzweig, Sebastian and Müller, Meinard. (2019). "Multi-Media Recordings of Traditional Georgian Vocal Music for Computational Analysis." The 9th International Workshop on Folk Music Analysis, Birmingham.

Scherbaum, Frank; Mzhavanadze, Nana; Arom, Simha; Rosenzweig, Sebastian and Müller, Meinard. (2020). Tonal Organization of the Erkomaishvili Dataset: Pitches, Scales, Melodies and Harmonies, Computational Analysis of Traditional Georgian Vocal Music. Potsdam: Universtatverlag Potsdam.

Tsuladze, Apolon. (1971). Etnograpiuli Guria [Ethnographical Guria]. Tbilisi: Sabchota Sakartvelo. 